\title{
Characterization of Ablation Product Radiation Signatures of PICA and FiberForm
}

\author{
Michael Winter ${ }^{*}$, Bradley D. Butler ${ }^{\dagger}$, Zhaojin Diao $^{\dagger}$, Francesco Panerai $^{\S}$, \\ Alexandre Martin ${ }^{* *}$, Sean C.C. Bailey ${ }^{\dagger \dagger}$ \\ University of Kentucky, Department of Mechanical Engineering, Lexington, KY 40506-0503, USA \\ Paul M. Danehy ${ }^{\dagger+}$, Scott Splinter $\$ \S$ \\ NASA Langley Research Center, Hampton, VA 23681-2199, USA
}

\begin{abstract}
Emission spectroscopy measurements in the post-shock layer in front of low density ablative material samples of different shapes were obtained in the NASA Langley HYMETS arcjet facility. A horizontal line of measurement positions was imaged on the entrance slit of the spectrometer allowing detection of the entire stagnation line in front of the samples. The stagnation line measurements were used to compare the post-shock layer emission signatures in front of PICA and FiberForm. The emission signatures of $\mathrm{H}, \mathrm{NH}$, and $\mathrm{OH}$ are characteristic for pyrolysis gases and consequently were only observed in front of the PICA samples. CN and $\mathrm{C}$ were found in front of both materials and are mainly due to interactions of the carbon fibers with the plasma. In all tests with instrumented samples, the emission of $\mathrm{Mn}, \mathrm{Cr}$, and $\mathrm{Ni}$ was observed when the thermocouple temperatures reached or exceeded $\sim 1,500 \mathrm{~K}$, strongly indicating erosion of the molten thermocouple tips. Temperatures in the post-shock layer were estimated from comparing the $\mathrm{CN}$ band emission to spectral simulation. The resulting rotational and vibrational temperatures were on the order of 7,000 to $9,000 \mathrm{~K}$ and close to each other indicating a plasma condition close to equilibrium. In addition to the stagnation line configurations, off-axis lines of observation were investigated to gather information about spalled particles in the flow. From a comparison of measured continuum emission with simulated Planck radiation, average particle temperatures along the measured line of observation were determined for two cases. Particle temperatures between 3,500 and 2,000 K were found. A comprehensive investigation of the entire amount of data set is ongoing.
\end{abstract}

\section{Introduction and Motivation}

SPACECRAFT entering into a planet's atmosphere experience significant heat loads while the kinetic energy is dissipated during deceleration of the vehicle. To protect the spacecraft, thermal protection systems (TPS) are used. For high entry speeds as for example experienced in re-entries from interplanetary missions, ablative materials are

\footnotetext{
* Assistant Professor, Department of Mechanical Engineering, 185 Ralph G. Anderson Building, Lexington, KY-40506-0503, USA, Associate Fellow AIAA.

$\dagger \mathrm{PhD}$ candidate, Department of Mechanical Engineering, 151 Ralph G. Anderson Building, Lexington, KY 40506-0503, USA, student member AIAA.

$¥ \mathrm{PhD}$ candidate, Department of Mechanical Engineering, 151 Ralph G. Anderson Building, Lexington, KY 40506-0503, USA.

$\S$ Postdoctoral Fellow, Department of Mechanical Engineering. Current address: AMA Inc. at NASA Ames Research Center, Moffett Field, CA 94035, USA, member AIAA.

** Associate Professor, Department of Mechanical Engineering, 261 Ralph G. Anderson Building, Lexington, KY-40506-0503, USA, Associate Fellow AIAA.

†t Associate Professor, Department of Mechanical Engineering, 283 Ralph G. Anderson Building, Lexington, KY-40506-0503, USA, member AIAA.

$\$$ Research Scientist, Advanced Measurements and Data Systems Branch, MS 493. Associate Fellow AIAA.

$\S \S$ Aerospace Engineer, Structural Mechanics and Concepts Branch, M/S 190, AIAA Member.
} 
often selected as the TPS. Ablators thermally, chemically and mechanically decompose during the hot reentry phase dissipating additional energy to the surrounding gas. The development of reliable TPS for atmospheric entries requires extensive material testing in ground test facilities under conditions relevant to high speed reentry, as provided by the NASA Ames arc-jets. ${ }^{1}$ However, even these high power facilities are not capable of reproducing real-flight conditions. Instead, an extrapolation of the ground test data to atmospheric entry is necessary. This is achieved through aerothermochemistry and material response simulation codes. ${ }^{2}$ These simulations require a thorough understanding of the conditions during ground testing and their relation to flight. A recent test campaign involving an experimental investigation of spallation (mechanical removal of material by shear stresses and friction) and gas-surface interactions of light weight ablators was carried out in the HYMETS facility at the NASA Langley Research Center. ${ }^{3,4}$ The data gained in such experiments will be provided as validation data for high fidelity material response codes, ${ }^{6,5}$ and spallation modeling efforts. ${ }^{7,8}$ For the investigation of gas-surface interactions as conducted in the HYMETS facility earlier but without spatial resolution, ${ }^{9}$ a setup was developed which images the stagnation line in front of a sample onto the entrance slit of a spectrometer. This arrangement provided an effective spatial resolution of $0.3 \mathrm{~mm}$ over a length of $22 \mathrm{~mm}$ covering the entire distance from the sample surface to a position upstream of the bow shock. This distance allows for monitoring the entire stagnation line and its time evolution over the duration of a test. Based on earlier work during testing of SPRITE models in the NASA Ames AHF arcjet facility, ${ }^{10}$ the UV-VIS wavelength region from $200 \mathrm{~nm}$ to $550 \mathrm{~nm}$ was selected. In this region, major ablation products of PICA (Phenolic Impregnated Carbon Ablator) and FiberForm are anticipated to radiate. PICA is NASA own state-of-the-art carbon/phenolic ablator within the low density ablators class, used successfully in Martian and Earth entry missions. FiberForm is the carbon fiber preform constituent of PICA. The longer wavelength range within the detection band allows for the detection of Planck radiation of solids bodies such as the spalled particles.

\section{Experimental Setups for HYMETS Testing}

The NASA Langley HYMETS arcjet is one of NASA's smallest and least expensive to operate ground test facilities for the experimental investigation of thermal protection materials. A $400 \mathrm{~kW}$ power supply is used to run a segmentedconstrictor direct-current electric arc heater, which serves as the arc plasma generator. Test gasses are injected tangentially into the bore to produce a vortex flow, which spin-stabilizes the electric arc of the plasma generator. The heated mixture is then accelerated through a convergent-divergent 8-degree half-angle Mach 5 conical nozzle with a 12.7-mm diameter throat. To increase the footprint of the arc and thus protect the electrodes from rapid oxidation, argon (Ar) is injected near the anode. After passing through the test section, the flow exhausts into a 0.6-m diameter by $0.9-\mathrm{m}$ long vacuum test chamber. A high capacity pumping system is used to evacuate the stagnated flow from the facility after being cooled. Depending on the tunnel conditions, the facility can be operated by a single technician, continuously, and for several hours. ${ }^{11,12}$

\section{A. Sample Configurations and Test Procedure}

Samples made of FiberForm and PICA were exposed to the HYMETS plasma. Three sample shapes (flat surfaced cylinders, hemispherical samples, and wedge samples) were tested. The cylindrical and the hemispherical samples had a diameter of 1.3 " $(33 \mathrm{~mm})$ and a length of 1 " $(25.4 \mathrm{~mm})$, the wedges had a squared cross section (1.3"x1.3" or $33 \mathrm{~mm}$ x $33 \mathrm{~mm})$ at the base and a total length of $2 "(50.8 \mathrm{~mm})$. Selected samples were instrumented with in-depth thermocouples. The nominal thermocouple locations were placed 0.25 ", 0.5 " and 0.75 " (or $6.35,12.7$, and $19.05 \mathrm{~mm}$, respectively) from the back surface of the samples, one on-axis, the other two 0.25 " $(6.35 \mathrm{~mm})$ off-

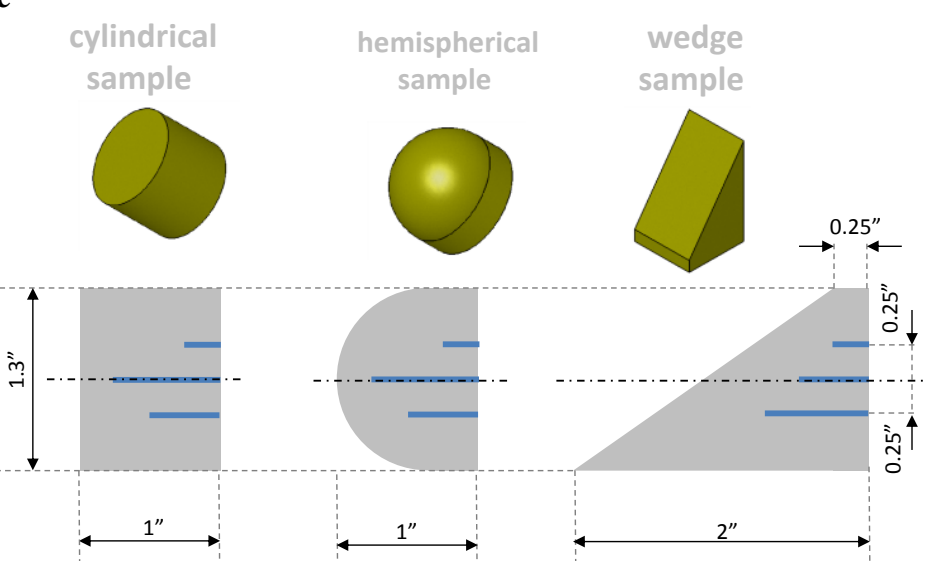

Figure 1. Sample shapes and thermocouple locations (blue lines). axis as illustrated in Fig. 1.

Tests were performed at conditions mainly defined by cold wall heat fluxes of 100,200 , and $400 \mathrm{~W} / \mathrm{cm}^{2}$ and stagnation pressures of 31.5, 32.5 and 25 Torr, respectively, with dry air as working gas. During each test, one pressure probe, one Gardon Gage heat flux probe and one calorimetric heat flux probe were inserted into the flow before and after

American Institute of Aeronautics and Astronautics 
sample insertion. The material samples were inserted for 30 seconds. Emission spectroscopy data were taken for both the probes and the material samples. Spallation was monitored through high speed cameras. Table 1 lists heat fluxes, sample materials and shapes, and locations of the emission spectroscopy measurements for the tests analyzed in the following. The presented analysis of the emission spectroscopy data focuses on tests at heat fluxes of 200 and 400 $\mathrm{W} / \mathrm{cm}^{2}$ in the stagnation region in front of cylindrical and hemispherical PICA and FiberForm (FF) samples and on analysis of average temperatures of spalled particles along the flat side of wedge samples.

Table 1. Test matrix for emission spectroscopy measurements.

\begin{tabular}{ccccc}
\hline \hline No & $\begin{array}{c}\text { Heat flux, } \\
\text { W/cm }\end{array}$ & Material & Sample shape & $\begin{array}{c}\text { Measured } \\
\text { location }\end{array}$ \\
\hline 1 & 200 & FF & Cylinder & Stag. Line \\
2 & 200 & PICA & Cylinder & Stag. Line \\
3 & 200 & FF & Hemi & Stag. Line \\
4 & 200 & PICA & Hemi & Stag. Line \\
5 & 400 & FF & Hemi & Stag. Line \\
6 & 400 & PICA & Hemi & Stag. Line \\
7 & 100 & FF & Cylinder & Off Stag. Line \\
8 & 200 & FF & Wedge & Off Stag. Line \\
\hline \hline
\end{tabular}

\section{B. Emission Spectroscopy}

For the emission spectroscopy measurements, an Andor Shamrock spectrometer with $500 \mathrm{~mm}$ focal length in combination with a Princeton Instruments PIXIS:400BR_eXcelon CCD was used for spectral dispersion and detection. The spectrometer observed the stagnation region in front of the material samples through a side window of the HYMETS facility. The 150 lines/mm grating allowed for a simultaneous detection of a wavelength range from $204 \mathrm{~nm}$ to $550 \mathrm{~nm}$ with a spectral resolution of $\sim 0.26 \mathrm{~nm}$. A $445 \mathrm{~mm}$ focal length parabolic mirror and several redirecting mirrors were used to image a horizontal line inside the test section onto the vertical entrance slit of the spectrometer. Since the sample position was not directly accessible through the side window, an additional periscope consisting of two mirrors angled at $45^{\circ}$ was placed inside the vacuum chamber to give a perpendicular line of sight onto the flow axis. Figure 2 illustrates the emission spectroscopy.

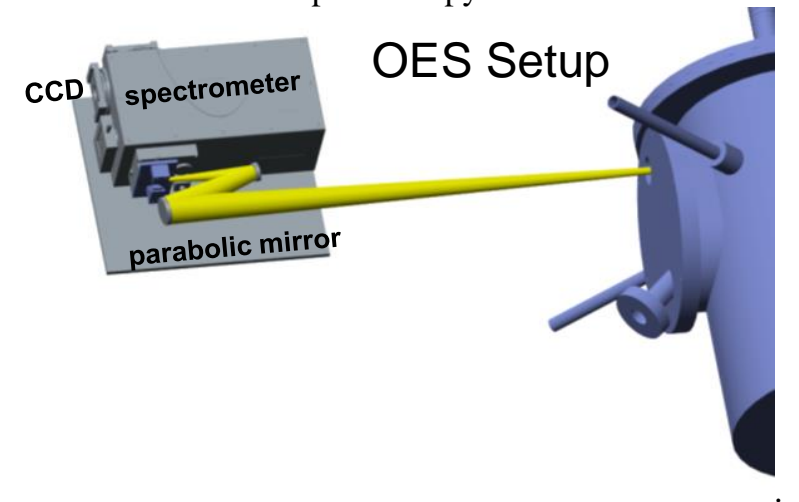

Figure 2. Setup for optical emission spectroscopy (OES) from the side with an Andor imaging spectrometer.

The CCD array height of $8 \mathrm{~mm}$ allowed for monitoring a line of $22 \mathrm{~mm}$ long horizontal line inside the HYMETS facility. Figure 3 illustrates a schematic of the different measured configurations for the three sample shapes presented in Figure 1. In addition to the center stagnation line, vertical offset positions above and alongside the sample, and parallel to the flat side of the wedge sample were measured for selected test conditions. This allowed for monitoring ablation products exiting the samples normal to the flow and detection of spalled particles outside the stagnation region. $^{4}$ 

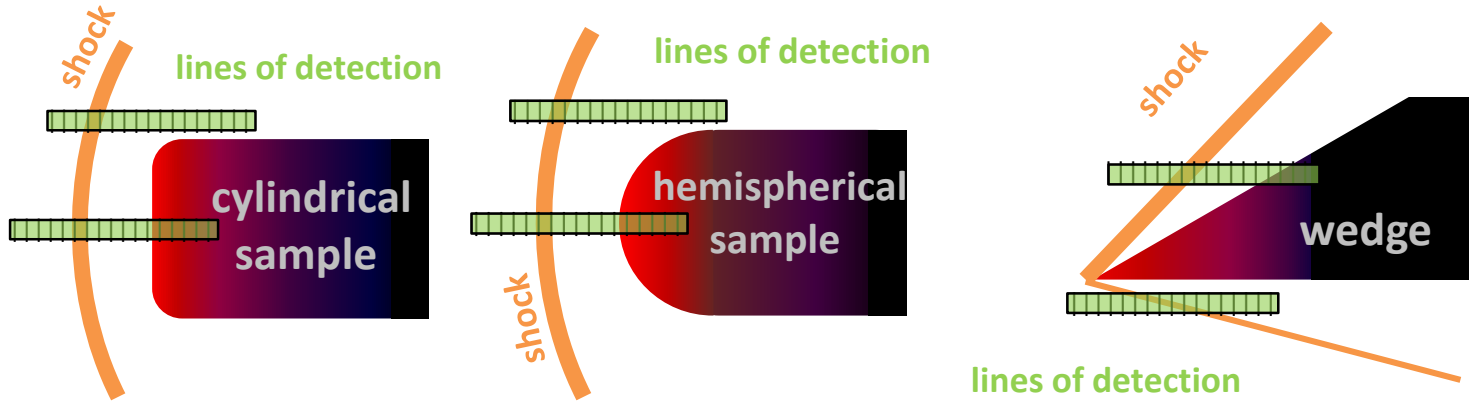

Figure 3. Lines of detection for different sample shapes.

Focusing and aligning the setup to the desired position of observation was done by tuning the grating to zero order (corresponding to a center wavelength of $0 \mathrm{~nm}$ ) therefore producing an image without spectral resolution. If the entrance slit is opened to its maximum (which for the spectrometer used here was $2.5 \mathrm{~mm}$ ) an image of the observed region is seen on the CCD camera. Before each test, an alignment specimen containing LEDs of different colors was placed on the stagnation line in contact to sample surface. Pictures of the sample were taken through the spectrometer showing the measurement location in reference to the surface. An example for this alignment procedure is given in Fig. 4. Intensity calibration was done through measuring the emission of a miniaturized spectral radiance source (Gigahertz-Optik BN-0102) calibrated between $300 \mathrm{~nm}$ and 1,100 nm and a deuterium lamp (Bentham CL3) calibrated to spectral irradiance between $200 \mathrm{~nm}$ and $400 \mathrm{~nm}$. The irradiance values from the Deuterium lamp were used to obtain the spectral sensitivity in the UV and were scaled to the radiance values obtained from the Gigahertz lamp in the overlapping spectral region to achieve a calibration to spectral radiance over the entire measured spectrum.
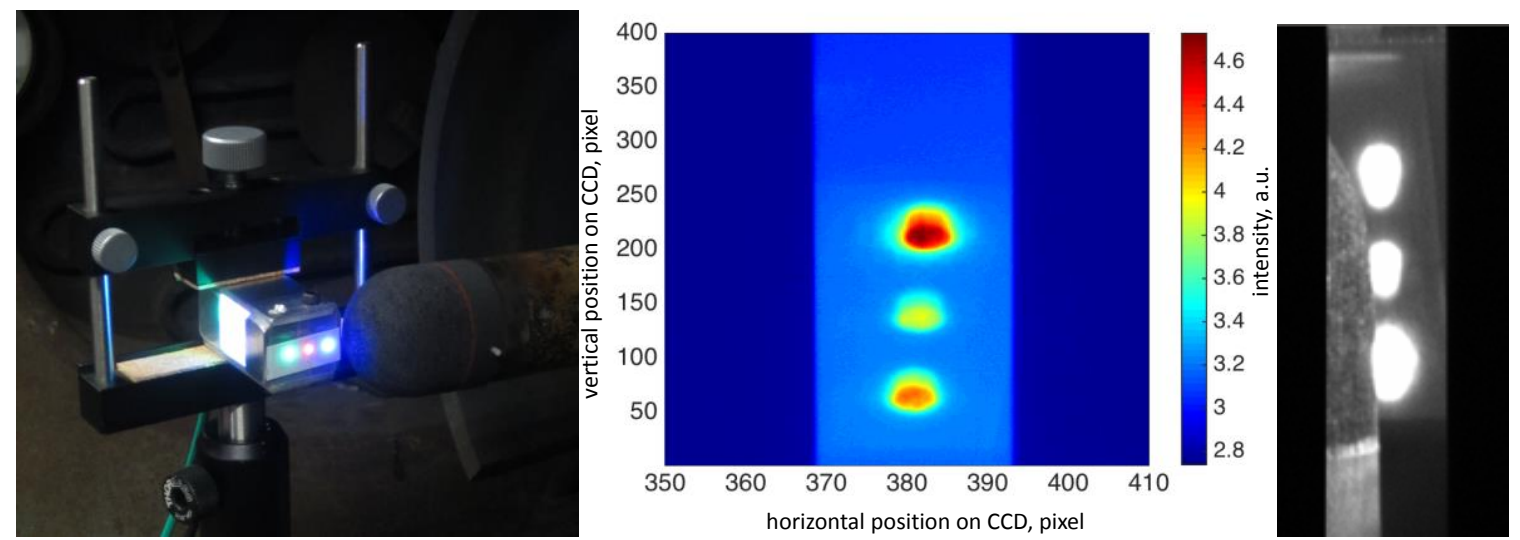

Figure 4. Alignment of the spectrometer set-up: a) LED specimen as mounted in front of a hemispherical FiberForm sample and b) as seen through the spectrometer; c) picture of the LEDs behind a hemispherical FiberForm sample as seen through the spectrometer with the grating set to zero order.

For optimal focusing, the spatial resolution of the setup on the HYMETS axis was defined by the size of one CCD pixel divided by the magnification of the setup obtained from the lens equation. In the current setup, a magnification (here defined as the ratio of image and object size) of 0.266 was obtained. Through calculating the image size of one CCD pixel if imaged onto the sample position, a spatial resolution of $75 \mu \mathrm{m} / \mathrm{pixel}$ on the HYMETS flow axis is achieved, if perfect focusing is assumed. However, emission spectroscopy is a line-of-sight method which means that locations in the optical path at distances different from the sharply imaged position also contribute to the measured signal. These locations will appear on the spectrometer entrance slit as blurred images. Geometrical optics tells us that the optical path of a focusing system diverges for locations before or behind the focused distance as illustrated in Fig. 5. At these off-focus locations, a larger area contributes to the measured signal. Therefore, the effective spatial resolution is not as fine as the value at the focused length. It is influenced by the spatial resolution at the radial border of the post-shock region. The smallest aperture in the optical path (here the mask on the focusing mirror with a diameter of 5/8") in combination with the corresponding distance to the focused length determines the divergence angle of the optical path, which, in return, determines the spatial resolution at a given distance to the focused position. Since, in the current case, the surface boundary layer is of highest interest in terms of spatial resolution the defining distance is given by the half the diameter of the observed sample. With typical sample diameters of $33 \mathrm{~mm}$ (design 
specification 1.3"), every 5 spectra on the CCD were binned, yielding an effective spatial resolution of $\sim 0.5 \mathrm{~mm}$. For typical shock stand-off distances of $\sim 3-5 \mathrm{~mm}$, the post shock layer was resolved with 6 measurement positions. Figure 5 illustrates the imaging and the determination of the effective spatial resolution.

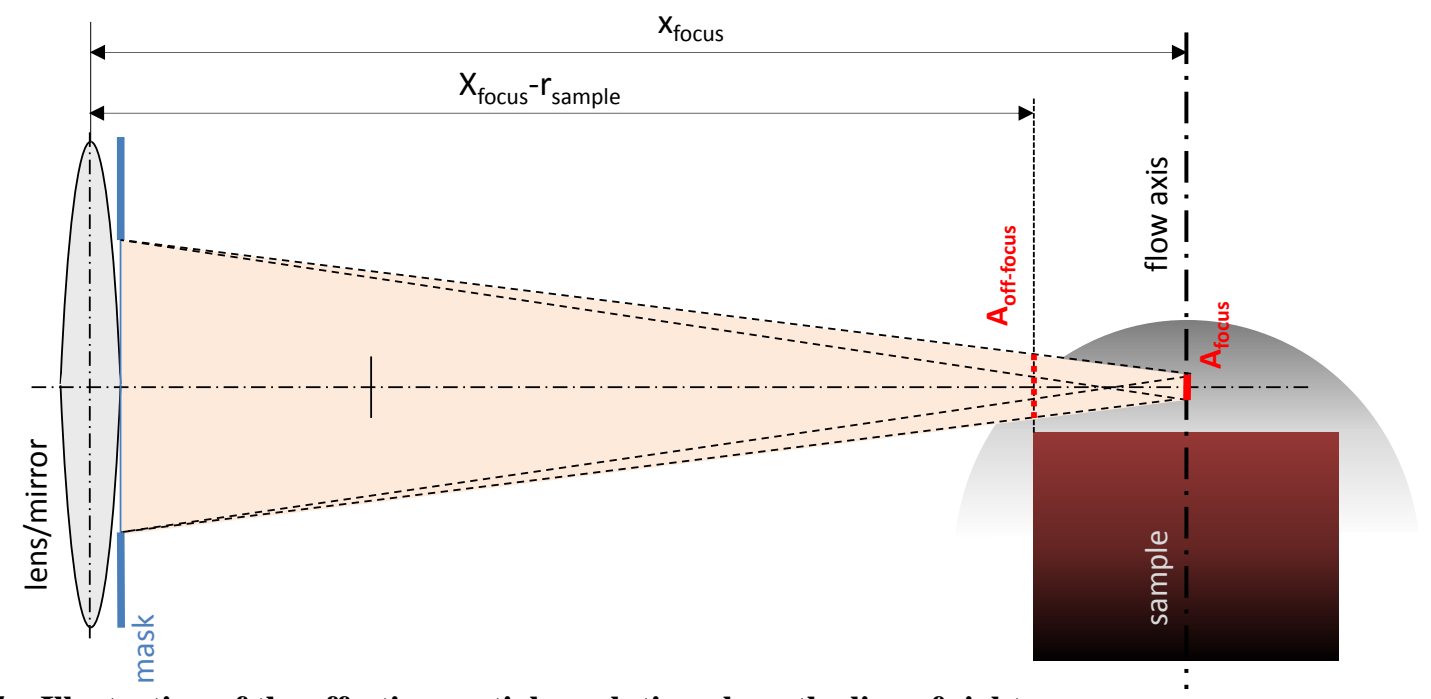

Figure 5. Illustration of the effective spatial resolution along the line of sight.

After insertion of the sample, the sample surface moves in the downstream direction over the test duration. This motion is a combination of surface recession and a deformation of the water-cooled sting arm which heats up while inside the plasma flow. The motion is observed on the CCD as demonstrated in Fig. 6 for a cylindrical FiberForm sample. In these images, the flow approaches the sample surface from the top of the image, the horizontal axis shows the wavelength of the emission. The sample surface is characterized by bright continuum emission at wavelengths greater than $400 \mathrm{~nm}$.
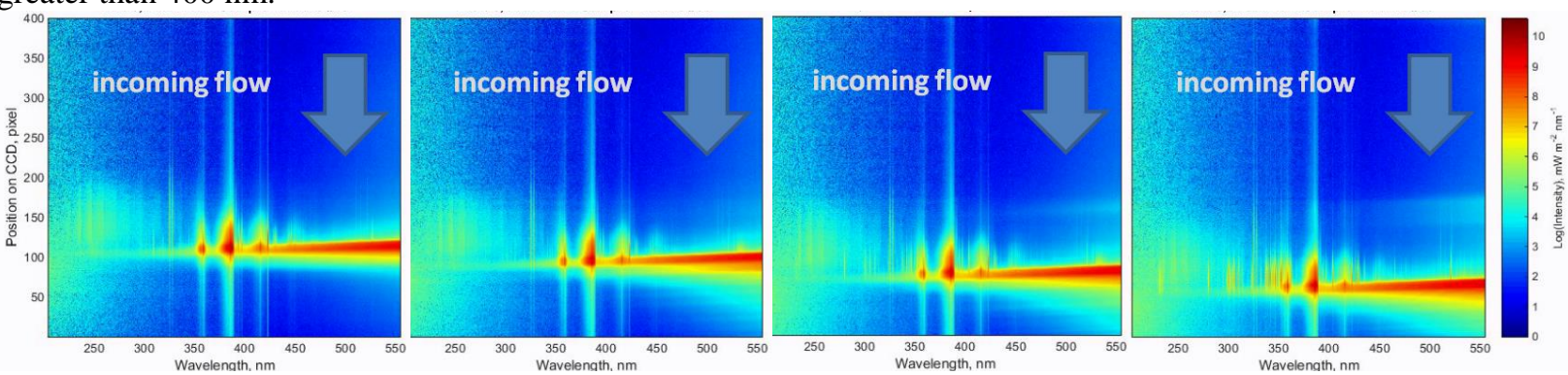

Figure 6. Time evolution of the spectra on the CCD in front of a cylindrical FiberForm sample at $200 \mathrm{~W} / \mathrm{cm}^{2}$.

\section{Experimental Data and Analysis}

The analysis of these data sets is considered a work in progress. So far, emphasis was given to the spectral characteristics of the stagnation region in front of hemispherical and cylindrical samples made of PICA and FiberForm at heat fluxes of 200 and $400 \mathrm{~W} / \mathrm{cm}^{2}$. As an example, a typical spectral image of the stagnation line in front of a cylindrical FiberForm sample at about $2 \mathrm{~s}$ after insertion into the plasma at a heat flux of $200 \mathrm{~W} / \mathrm{cm}^{2}$ (case 1 in Table 1) is shown in Fig. 7. The horizontal axis represents the wavelength domain from $205 \mathrm{~nm}$ to $555 \mathrm{~nm}$, the vertical direction the position along the stagnation line with the flow approaching the surface from the top. The radiance is displayed with a color code on log scale and adjusted to show weaker features. Several general features dominating the spectra are NO radiation in the UV, strong copper lines at 324.75 and $327.4 \mathrm{~nm}$ due to erosion products from the arc-jet electrodes, $\mathrm{CN}$ bands from the interaction of ablation products with the air plasma dominating the spectrum between 340 and $440 \mathrm{~nm}$, and continuum emission from the glowing surface above $450 \mathrm{~nm}$. Weaker emission is seen from carbon atom lines as well as $\mathrm{Ni}, \mathrm{Mn}$, and $\mathrm{Cr}$ (interpreted as erosion from the in-depth thermocouples) and, in the case of a PICA sample, $\mathrm{NH}$ and $\mathrm{OH}$ from interaction with the pyrolysis gases. Section A will concentrate on identification of radiating species and the distribution of their emission along the stagnation line and over time. 


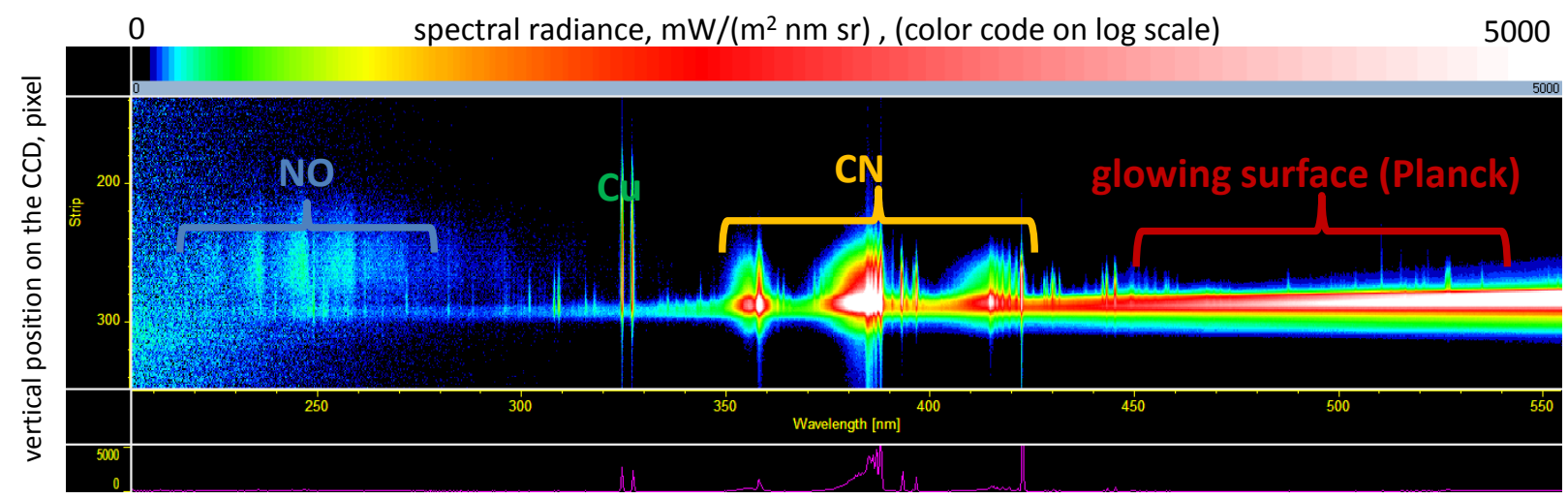

Figure 7. Spectral image of the stagnation line in front of a cylindrical FiberForm sample at about $2 \mathrm{~s}$ after insertion into the plasma at a heat flux of $200 \mathrm{~W} / \mathrm{cm}^{2}$ (case 1 in Table 1). The radiance is displayed with a color code on log scale and adjusted to show weaker features.

The emission of $\mathrm{CN}$ and $\mathrm{C}_{2}$ was used to estimate temperatures in the post-shock layer through comparison with theoretical spectra simulated with the NEQAIR code..$^{13,14}$ The method and results are discussed in section B.

In addition to the stagnation line data, off-axis measurements were performed with particular respect to spalled particles in the flow. Examples of preliminary results are presented in section C. Detailed results in comparison with high-speed camera data of spalled particles will be discussed in a separate publication.

\section{A. Emission Spectroscopy Signatures in the Stagnation Region of FiberForm and PICA}

The complete stagnation line from the inflow ahead of the shock to positions on the sample's side surface was covered through these measurements. Due to recession and thermal deformation of the sting arm, the horizontal position of the sample surface moved by about $3 \mathrm{~mm}$ over the typical insertion time of 30 seconds. During the analysis process, this movement was taken into account to be able to analyze selected distances relative to the current sample surface over time. Figures 8 and 9 illustrate the emitting species, detailed comparisons of emission signatures in front of PICA and FiberForm follow later.

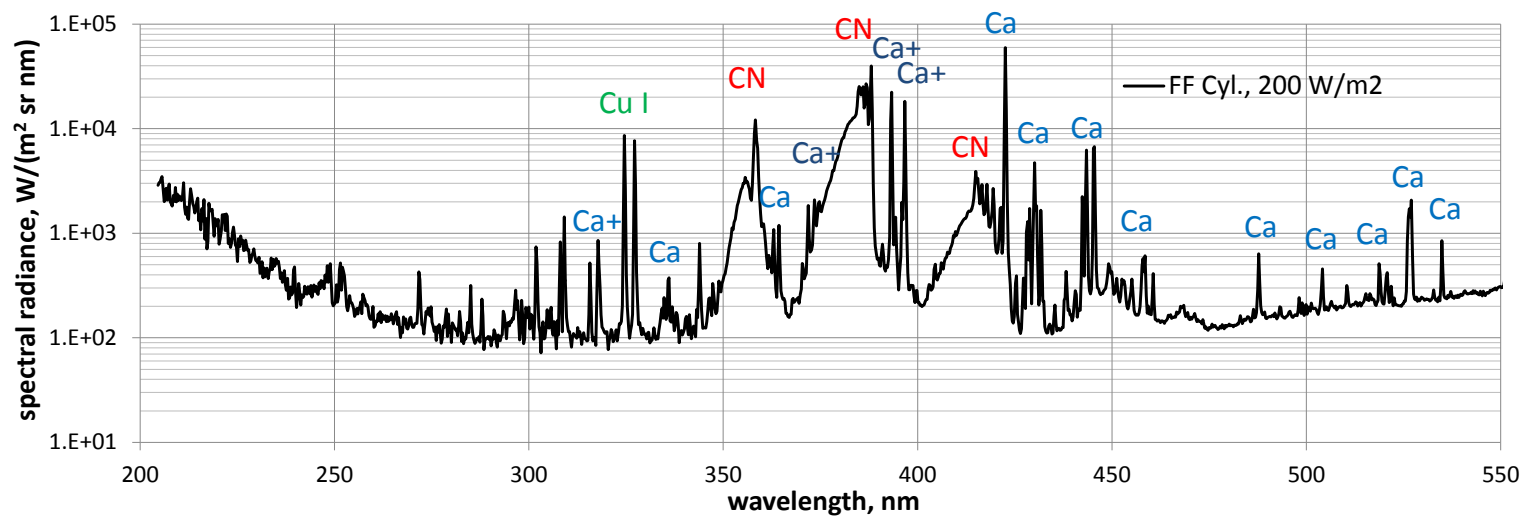

Figure 8. Emission spectrum collected at $\sim 1 \mathrm{~s}$ after insertion, at $\sim 1 \mathrm{~mm}$ in front of the surface for a cylindrical FiberForm sample tested at $200 \mathrm{~W} / \mathrm{cm}^{2}$.

The spectra are dominated by the emission of $\mathrm{CN}$, with the bands being generally stronger in front of PICA. Numerous emission lines of $\mathrm{Ca}$ and $\mathrm{Ca}+$ are visible both in front of FiberForm and PICA, which is explained by clusters of calcium introduced during the manufacturing process of FiberForm. ${ }^{15,16}$ Copper emission lines around 324 $\mathrm{nm}$ are almost always present in the spectra due to cathode erosion in the arc-jet. One main difference between PICA and FiberForm is the presence of species containing hydrogen, in particular NH with its peak emission at $336 \mathrm{~nm}$ and $\mathrm{OH}$ peaking at $306 \mathrm{~nm}$ and the $\mathrm{H}_{\beta}$ at $486.1 \mathrm{~nm}$. At higher heat fluxes, carbon lines appear in the spectrum, the strongest emission being noticed at $247.9 \mathrm{~nm}$ Above $500 \mathrm{~nm}$ the emission of the $\mathrm{C}_{2} S$ wan system is observed for both materials. The continuum like emission increasing from $250 \mathrm{~nm}$ to lower wavelengths is potentially an artifact of background noise. Due to the tremendously decreasing sensitivity of the setup (mainly caused by the mirrors in the periscope) in 
this wavelength region such artifacts might be increased through the high calibration factors and cause a continuum like shape.

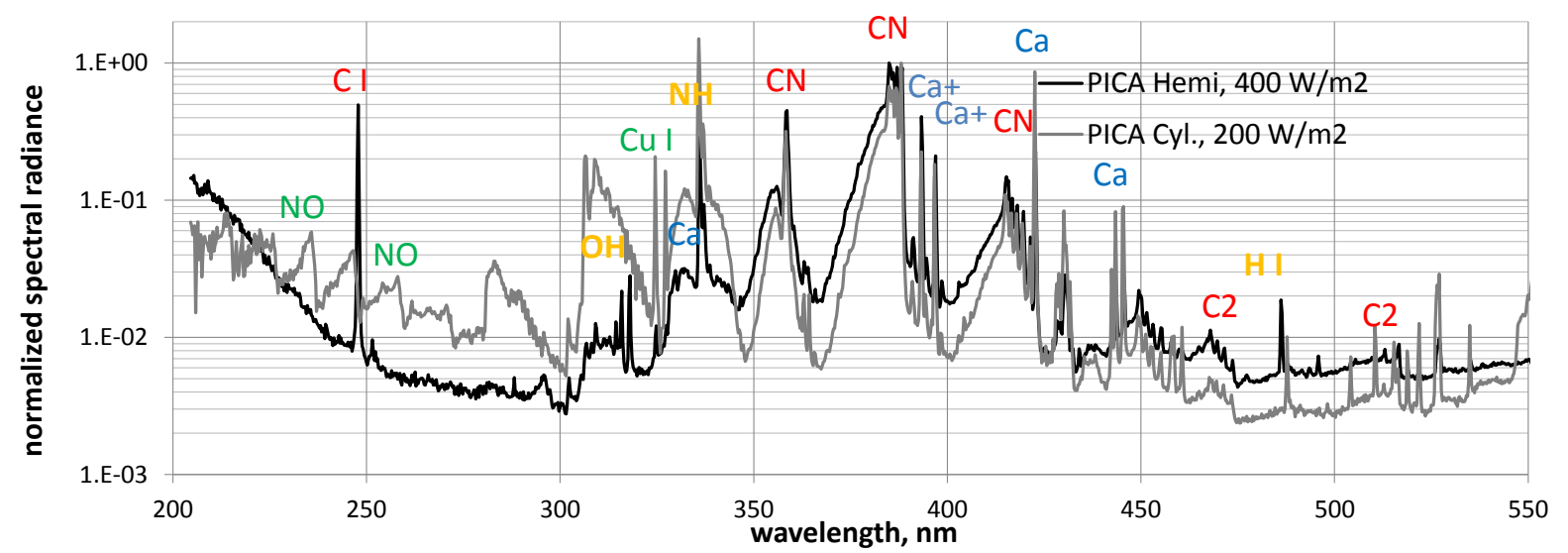

Figure 9. Emission spectra collected at $\sim 1 \mathrm{~s}$ after insertion, for a cylindrical PICA tested at $200 \mathrm{~W} / \mathrm{cm}^{2}$ and a hemispherical PICA sample tested at $400 \mathrm{~W} / \mathrm{cm}^{2}$. The spectra were normalized to the maximum $\mathrm{CN}$ emission to illustrate the identification of the major emitting species.

Figures 10 and 11 show a direct comparison of emission spectra in front of hemispherical and cylindrical samples of FiberForm and PICA at heat fluxes of 200 and $400 \mathrm{~W} / \mathrm{cm}^{2}$ at a distance of $1 \mathrm{~mm}$ to the sample surface about one second after insertion into the plasma flow.
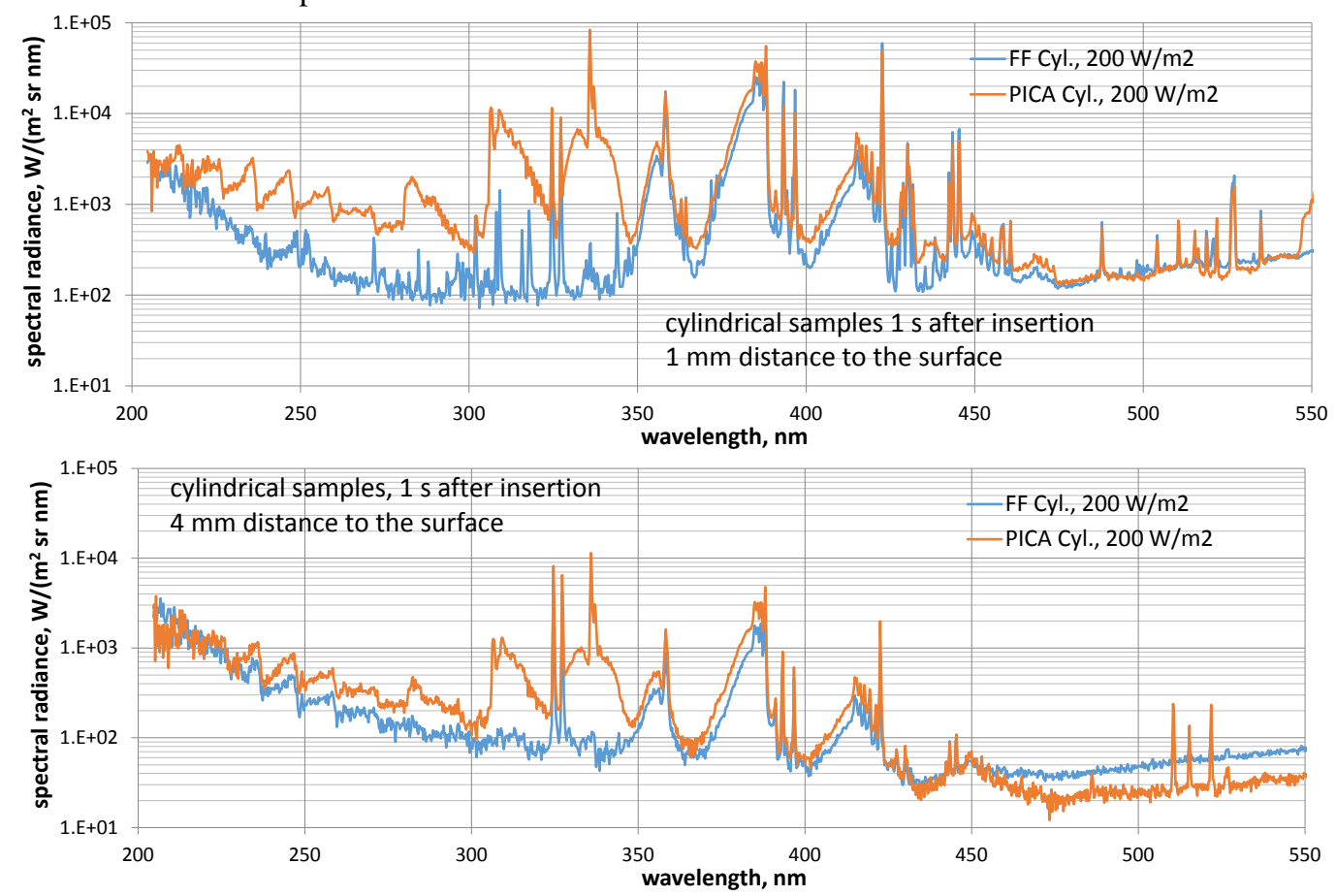

Figure 10. Comparison of emission spectra collected 1s after sample insertion, for cylindrical PICA and FiberForm samples tested at $200 \mathrm{~W} / \mathrm{cm}^{2}$. Spectra collected 1 (top) and $4 \mathrm{~mm}$ (bottom) ahead of the surface are shown.

As mentioned earlier, one main difference between PICA and FiberForm is the presence of species containing hydrogen, in particular NH with its peak emission at $336 \mathrm{~nm}$ and $\mathrm{OH}$ peaking at $306 \mathrm{~nm}$. However, clear structures of $\mathrm{NO}$ emission can be seen in that region in front of the PICA surface (in particular in the post-shock region in front of the cylindrical sample) but seem to be absent in front of FiberForm. At larger distances to the surface (illustrated in Fig. 10 showing spectra at $4 \mathrm{~mm}$ distance which is still inside the post-shock layer), NO emission appears in front of both materials. At higher heat fluxes as shown in Fig. 11, the same species are identified although the band systems

American Institute of Aeronautics and Astronautics 
of $\mathrm{OH}$ and $\mathrm{NO}$ in front of PICA vanish. Instead, the hydrogen line $\mathrm{H}_{\beta}$ at $486.1 \mathrm{~nm}$ becomes visible in front of PICA and carbon atomic lines appear in front of both materials, the strongest emission being noticed at $247.9 \mathrm{~nm}$.
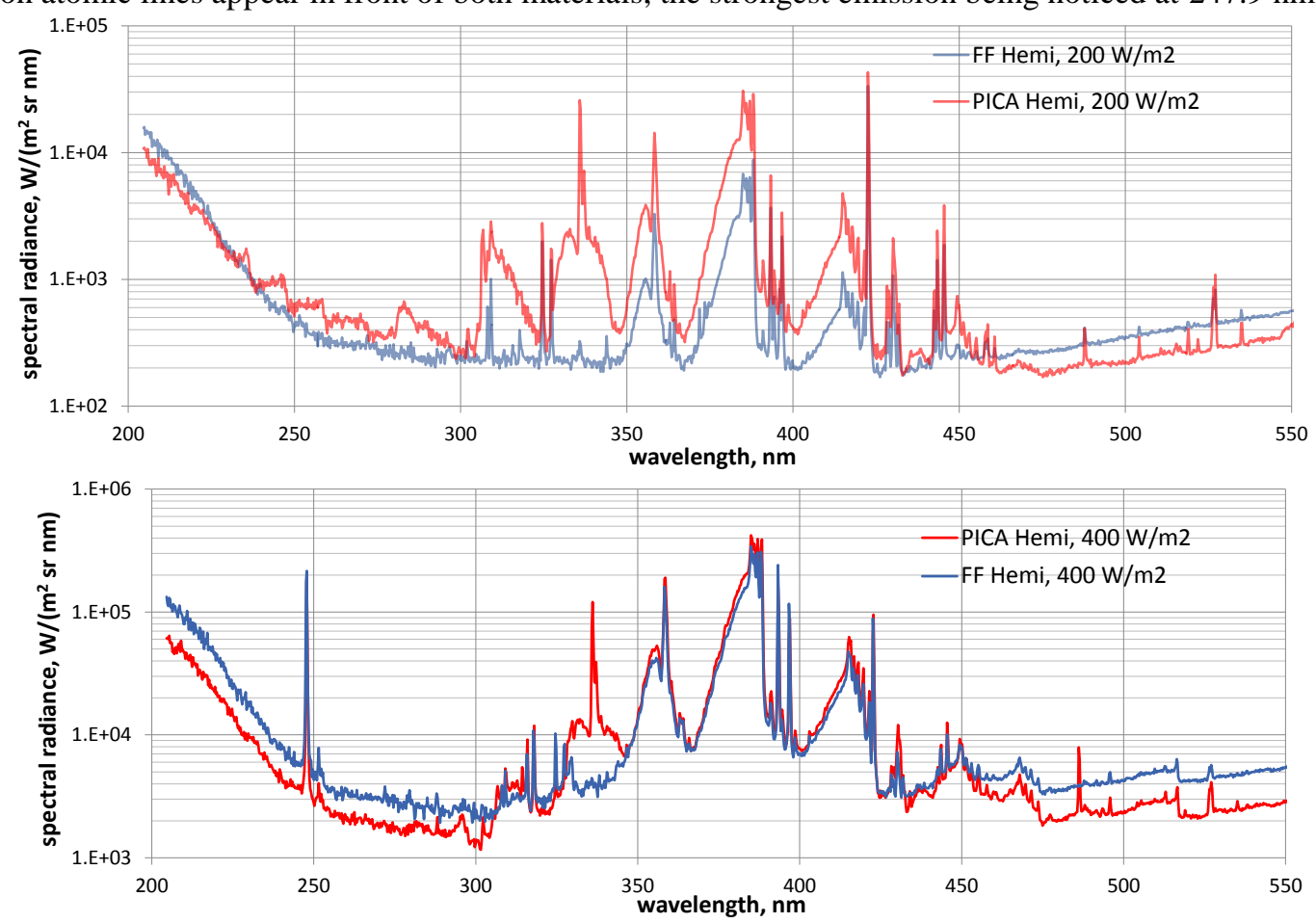

Figure 11. Emission spectra at a distance of about $1 \mathrm{~mm}$ to hemispherical samples of PICA and FiberForm at a heat fluxes of 200 and $400 \mathrm{~W} / \mathrm{cm}^{2}$ about 1 second after sample insertion.

To monitor the emission of selected species, integrals over the corresponding atom or molecule were determined by integrating the emission lines of interest and compensating a potential background (e.g. from contributions of other molecular or atom species or from continuum emission) by subtracting an underlying trapezoid area from the line integral. Furthermore, a second integration over the whole post-shock layer was performed yielding the total emission of the line under investigation in the field of view of the spectrometer. The use of peak intensities, though often found in similar analysis, is not recommended since the position of the peak intensity can be located between pixels and therefore show significant deviations from the true peak value.

Figure 12 shows examples for the spatial distribution of the emission of $\mathrm{NH}, \mathrm{CN}$ and $\mathrm{C}$ in the post shock layer over time after insertion. With increasing time in the flow, the $\mathrm{NH}$ (and $\mathrm{H}$, although not shown in Fig. 12) emission vanishes. The emission of $\mathrm{C}$ and $\mathrm{CN}$, however, remains visible throughout the entire period the samples are in the flow. The behavior is similar for both materials other than the time traces of species containing hydrogen. Therefore, the emission of $\mathrm{C}$ and $\mathrm{CN}$ is stronger coupled to the carbon fibers than to pyrolysis (compare also Fig. 16).
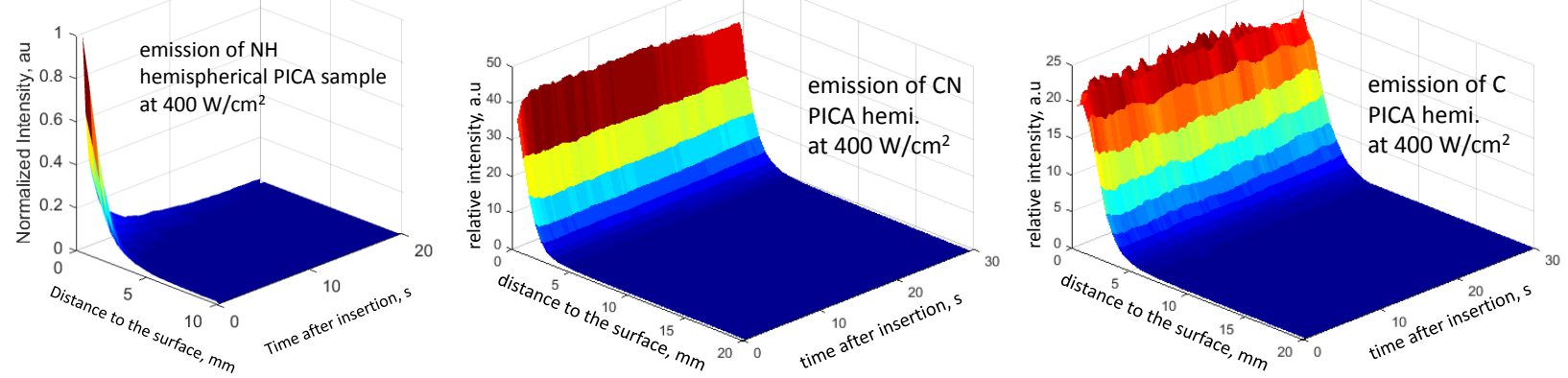

Figure 12. Time evolution of the spatial distribution along the stagnation line of the emission of $\mathrm{NH}$, $\mathrm{CN}$, and $C$ in front of a hemispherical PICA sample at a heat flux of $400 \mathrm{~W} / \mathrm{cm}^{2}$.

The time decay of $\mathrm{H}$ (Figure 13) and NH (Figure 14) is very strong for the hemispheric sample at $400 \mathrm{~W} / \mathrm{cm}^{2}$. Since the only source of hydrogen is through pyrolysis gases, one possible interpretation of these data is that blowing through 
the front surface of the samples decreases significantly in the first few seconds after insertion for this high heat flux. The decay of $\mathrm{NH}$ emission for a hemispherical sample at $200 \mathrm{~W} / \mathrm{cm}^{2}$ is significantly slower. For the cylindrical PICA sample at $200 \mathrm{~W} / \mathrm{cm}^{2}$, the decay is slowest and $\mathrm{NH}$ is visible until the end of the test indicating pyrolysis gases are present close to the surface over the entire test time. The $\mathrm{NH}$ and $\mathrm{H} \mathrm{I}$ emission decay close to the surface with time is illustrated in Figs. 13 and 14.
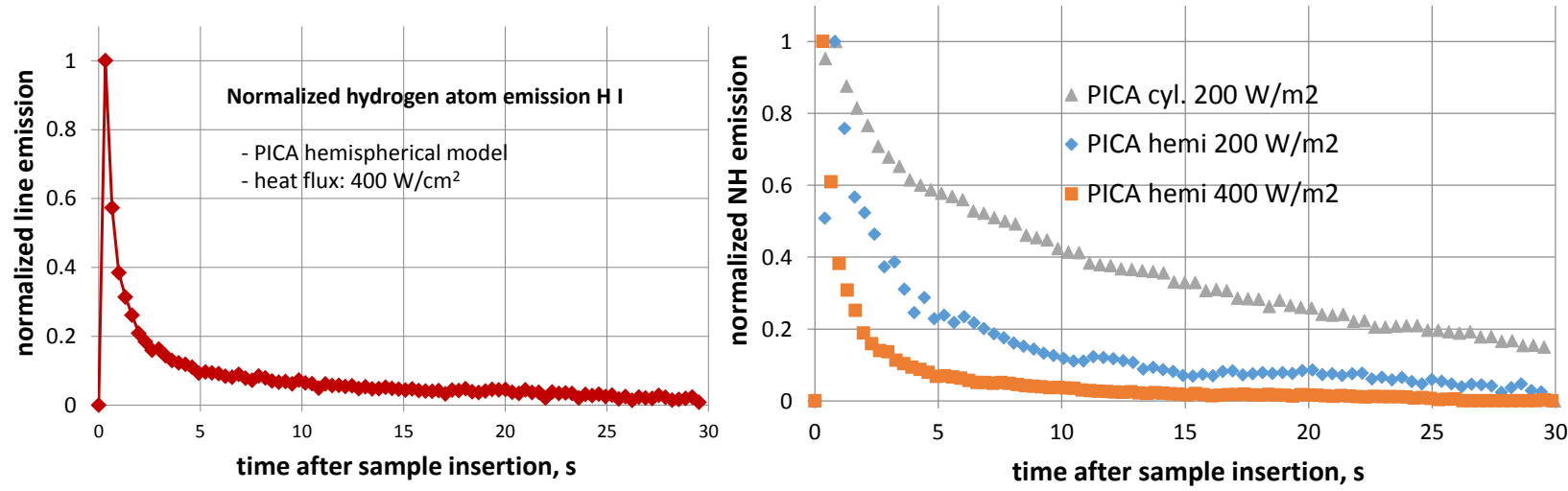

Figure 13. Decay of the emission of atomic oxygen $\mathrm{H} I$ in front of a hemispherical PICA sample at a heat flux of $400 \mathrm{~W} / \mathrm{cm}^{2}$.

Figure 14. Decay of the emission of $\mathrm{NH}$ in front of a hemispherical PICA sample at heat fluxes of 200 and 400 $\mathrm{W} / \mathrm{cm}^{2}$ and in front of a cylindrical PICA sample at a heat flux of $200 \mathrm{~W} / \mathrm{cm}^{2}$.

For $\mathrm{CN}$ and $\mathrm{C}$, the spatial profiles do not change significantly over time, therefore their distribution along the stagnation line is best described as the mean values over time as shown in Fig. 15 for a hemispherical PICA sample at a heat flux of $400 \mathrm{~W} / \mathrm{cm}^{2}$. The standard deviation over the time trace is added to demonstrate the constant behavior over time. A comparison of time averaged $\mathrm{CN}$ band intensity distributions along the stagnation line in front of the different samples at the two heat flux values is shown in Fig. 16.

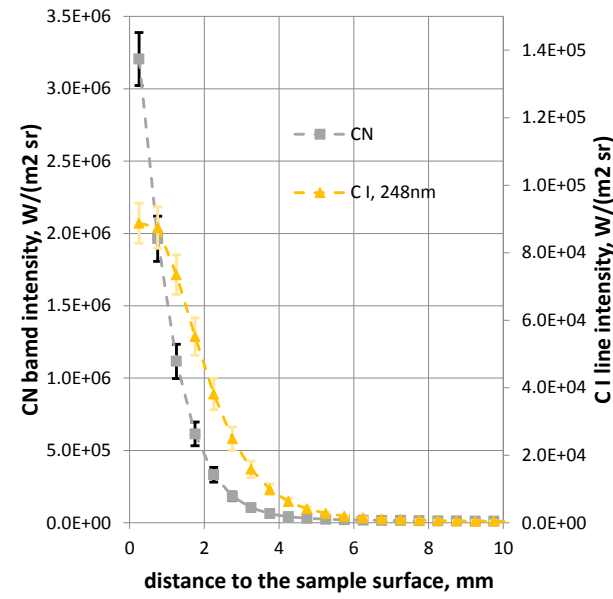

Figure 15. CN band intensity and $C I$ line intensity distributions along the stagnation line in front of a hemispherical PICA sample at a heat flux of $400 \mathrm{~W} / \mathrm{cm}^{2}$. Error bars are +/- one standard deviation.

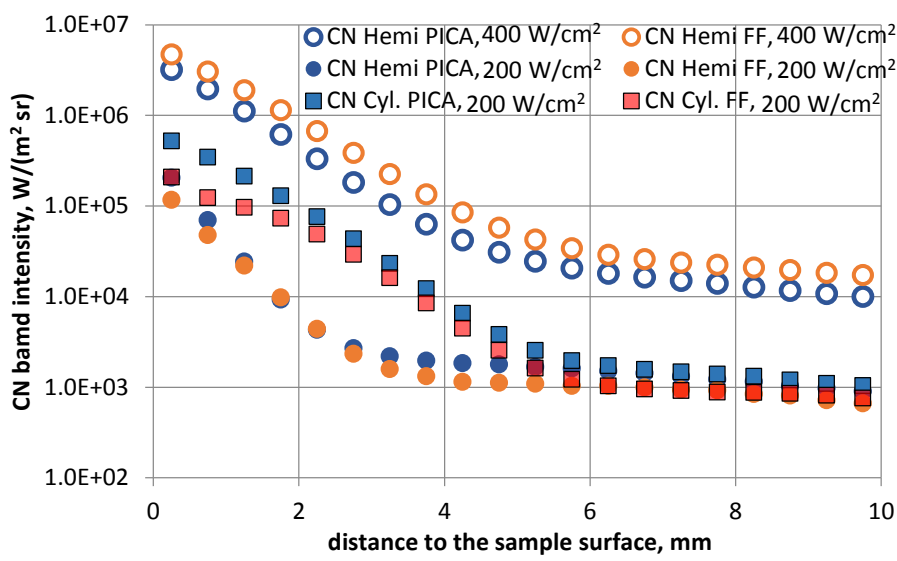

Figure 16. CN band intensity distributions along the stagnation line in front of hemispherical PICA and FiberForm samples at $400 \mathrm{~W} / \mathrm{cm}^{2}$ and in front of hemispherical and cylindrical PICA and FiberForm samples at $200 \mathrm{~W} / \mathrm{cm}^{2}$. 
Figure 16 shows that the $\mathrm{CN}$ emission increases with heat flux. In the post-shock layer in front of hemispherical samples, $\mathrm{CN}$ radiation is stronger in front of PICA for $400 \mathrm{~W} / \mathrm{cm}^{2}$, for $200 \mathrm{~W} / \mathrm{cm}^{2}$, nearly the same emission is seen in front of both materials. For the same heat flux of 200 $\mathrm{W} / \mathrm{cm}^{2} \mathrm{CN}$ emission is stronger in front of cylindrical samples which is explained by the larger boundary layer in both radial and axial direction compared to hemispherical surfaces. For cylindrical samples, CN emission is stronger in front of the FiberForm surface than in front of PICA. The difference reduces with distance to the surface.

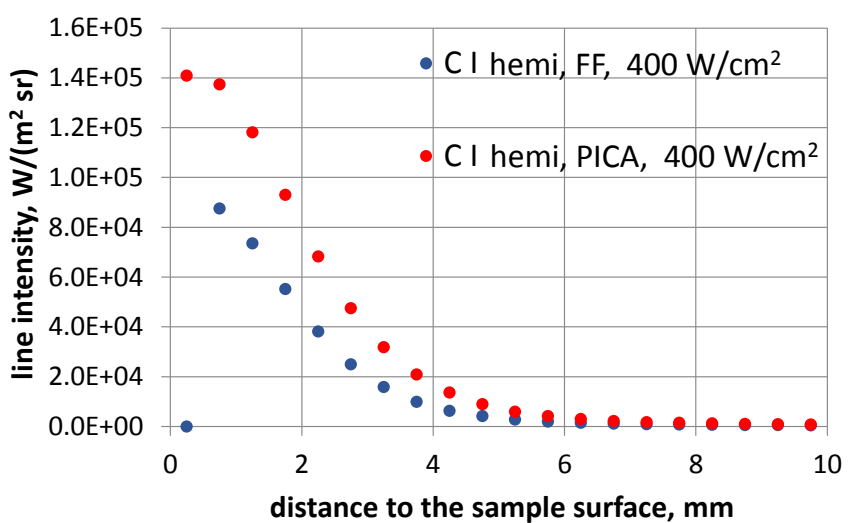

Figure 17. C I line intensity distributions along the stagnation line in front of hemispherical PICA and FiberForm samples at 400 $\mathrm{W} / \mathrm{cm}^{2}$.

The strongest carbon atom emission comes from a line at $\sim 248 \mathrm{~nm}$. This C I line is barely visible for the lower heat flux case but is quite strong for $400 \mathrm{~W} / \mathrm{m}^{2}$. If the two materials are compared, carbon atom emission is higher by almost 50\% in front of the PICA surface.

Figure 18 shows time traces of line intensities of $\mathrm{Ca}$ in $\mathrm{W} /\left(\mathrm{sr} \mathrm{m}^{2}\right)$ and normalized to their values shortly after model insertion. While most of the other ablation products show a rather smooth time distribution, the Ca emission - in particular in front of PICA surfaces - may show a more erratic behavior with sudden peaks. This indeed supports the assumption of calcium clusters inside the material. The general trend is a decrease with test time. This decrease, however, is significantly faster in front of FiberForm than in front of PICA. In addition, the amount of emission is significantly stronger in front of PICA. The same general trends hold for $\mathrm{Ca}+$ as shown in Figure 19. In front of a hemispherical FiberForm model at $200 \mathrm{~W} / \mathrm{cm}^{2}$, almost no Ca+ emission is observed while it is clearly present in front of PICA of the same geometry and with the same heat load.
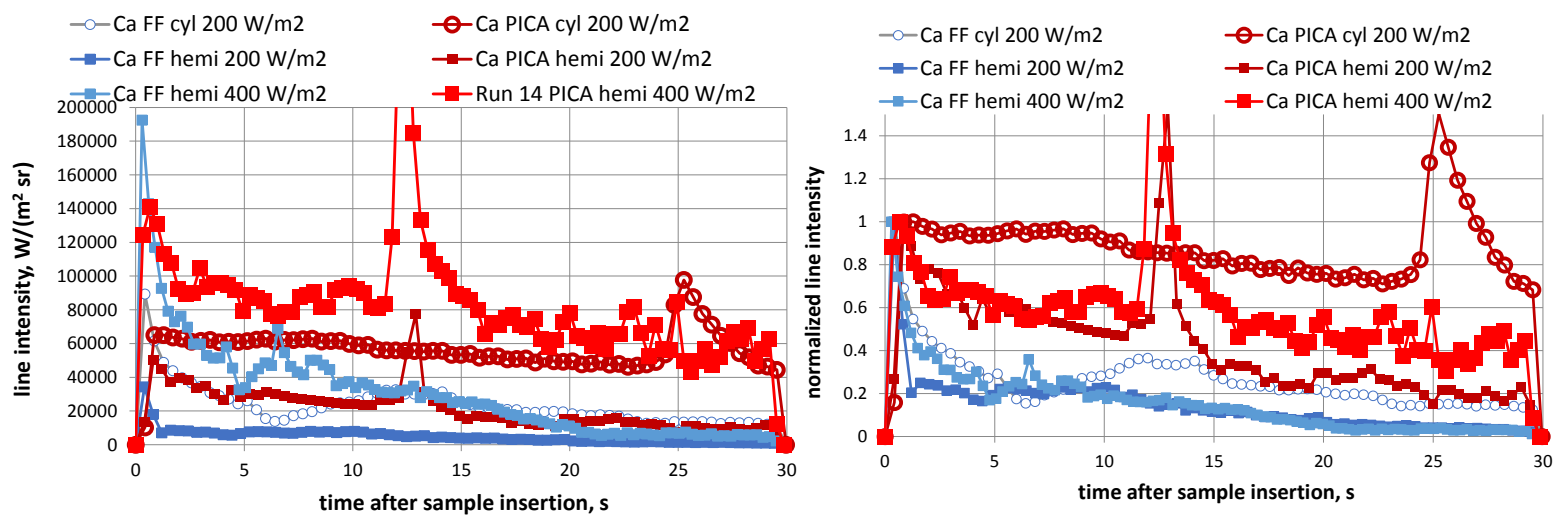

Figure 18. Line emission of Ca in front of PICA and FiberForm samples in $\mathrm{W} /\left(\mathrm{m}^{2} \mathrm{sr}\right)$ and normalized to the values right after model insertion.
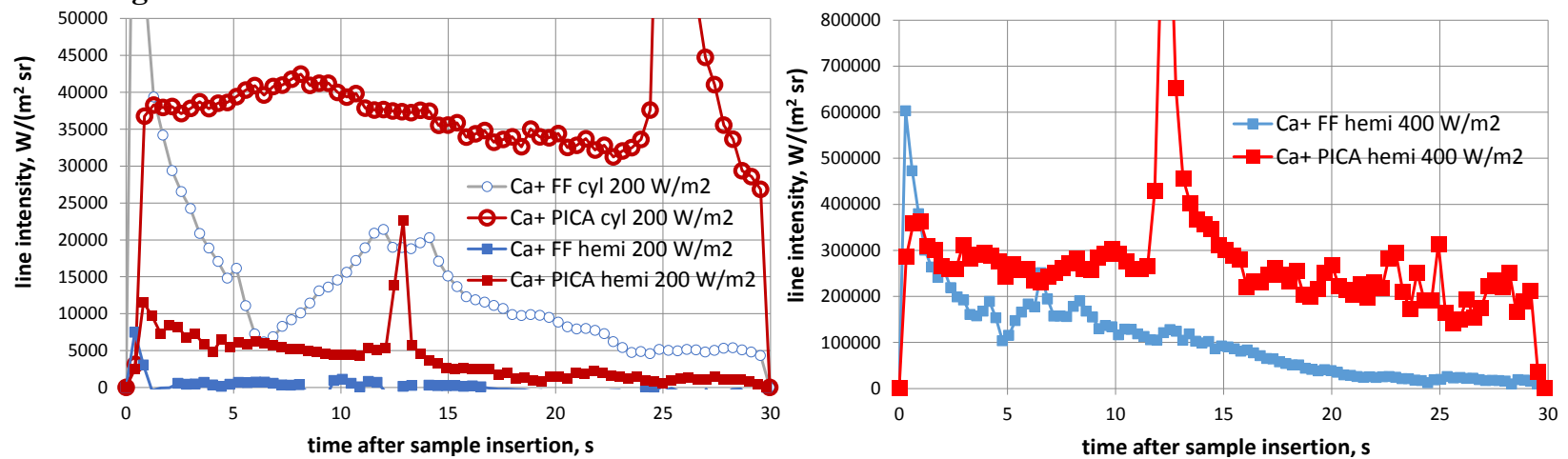

Figure 19. Line emission of Ca+ in front of PICA and FiberForm samples at heat fluxes of $200 \mathrm{~W} / \mathrm{cm}^{2}$ (left) and $400 \mathrm{~W} / \mathrm{cm}^{2}$ (right).

American Institute of Aeronautics and Astronautics 
The samples were instrumented with in-depth type $\mathrm{K}$ thermocouples chiefly made of $\mathrm{Ni}$ and $\mathrm{Cr}$ (Chromel: 80\% $\mathrm{Ni}$ + 20\% Cr and Alumel: $95 \% \mathrm{Ni}, 2 \% \mathrm{Mn}$, and $2 \% \mathrm{Al}$, melting point at $\sim 1,700 \mathrm{~K}$ ) to measure the time trace of the temperature distribution inside the material. At a certain time after insertion, $\mathrm{Ni}, \mathrm{Cr}$, and $\mathrm{Mn}$ emission lines were detected in the emission spectra. Correlation can be found when comparing the time evolution of their line intensities to the thermocouples time recordings. As shown in Figs. 20 to 22, the emission lines of $\mathrm{Ni}, \mathrm{Cr}$ and $\mathrm{Mn}$ appear when the thermocouple (TC) closest to the surface exceeds its maximum operation temperature near 1,500 K. Typically, Mn shows up first, closely followed by $\mathrm{Cr}$ and Ni. Conversely, for the PICA cylinder tested at $200 \mathrm{~W} / \mathrm{cm}^{2}$, the indepth temperatures never reach 1,500 $\mathrm{K}$ and no emission of $\mathrm{Ni}, \mathrm{Cr}$, or $\mathrm{Mn}$ is seen in the emission spectra.
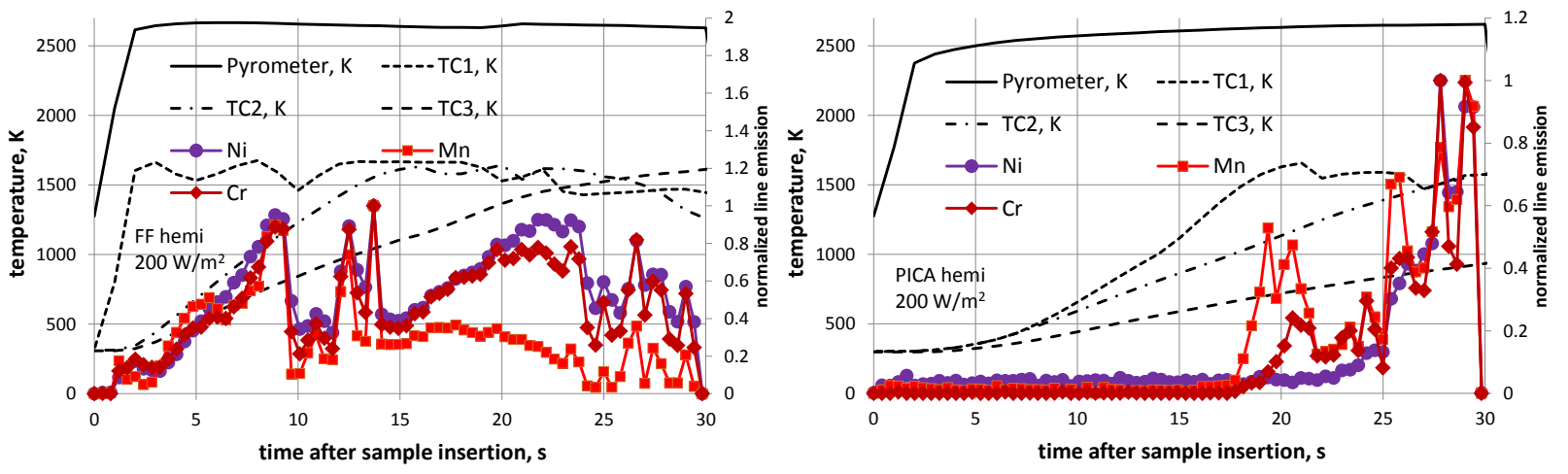

Figure 20. Time evolution of $\mathrm{Ni}, \mathrm{Mn}$, and $\mathrm{Cr}$ line emission, along with surface and in-depth temperatures for hemispherical FiberForm (left) and PICA (right) samples at a heat flux of $200 \mathrm{~W} / \mathrm{cm}^{2}$.
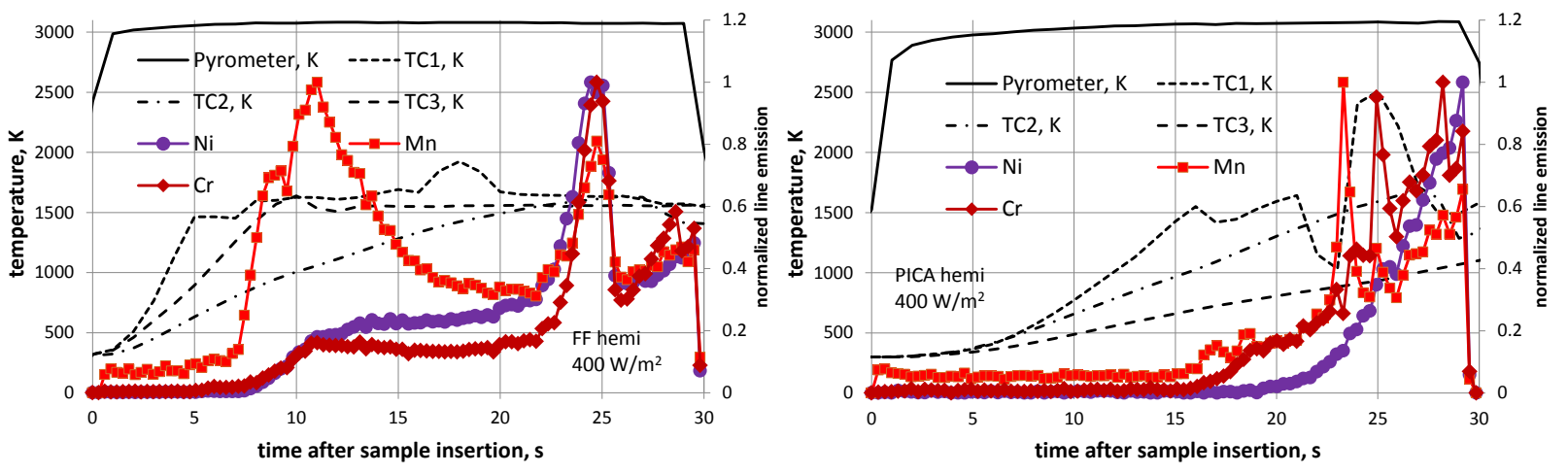

Figure 21. Time evolution of $\mathrm{Ni}, \mathrm{Mn}$, and $\mathrm{Cr}$ line emission, along with surface and in-depth temperatures for hemispherical FiberForm (left) and PICA (right) samples at a heat flux of $400 \mathrm{~W} / \mathrm{cm}^{2}$.

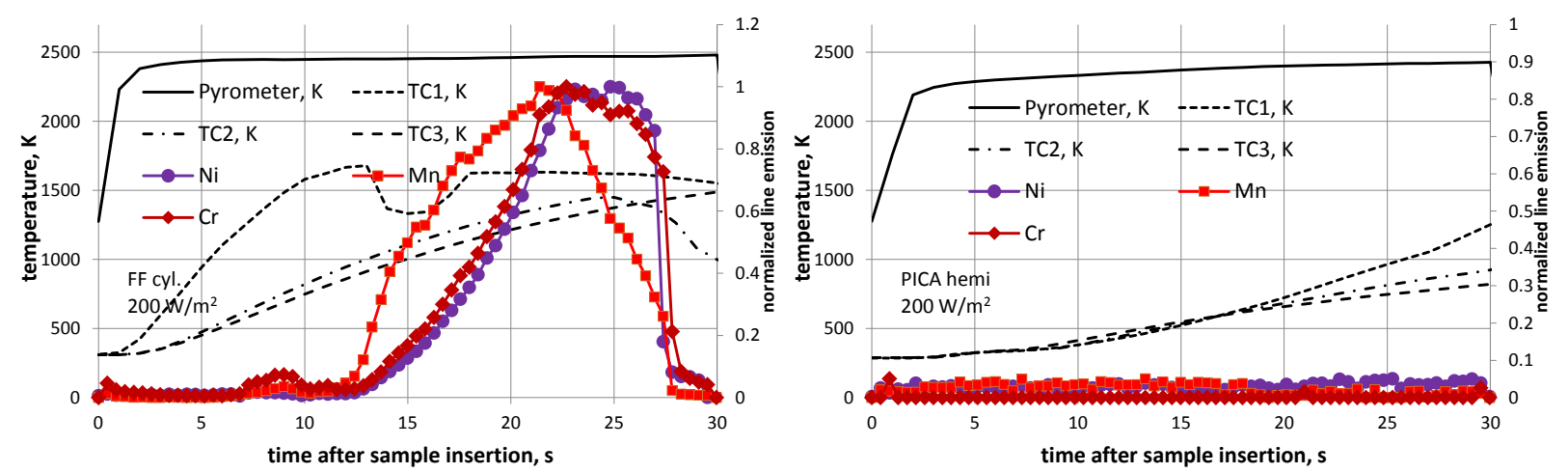

Figure 22. Time evolution of $\mathrm{Ni}, \mathrm{Mn}$, and $\mathrm{Cr}$ line emission, along with surface and in-depth temperatures for a cylindrical FiberForm (left) and PICA (right) samples at a heat flux of $200 \mathrm{~W} / \mathrm{cm}^{2}$.

American Institute of Aeronautics and Astronautics 


\section{B. Temperatures in the Post Shock Layer}

To get estimates of the temperature in the post shock layer, the molecular band emission of $\mathrm{CN}$ was compared to theoretical spectra simulated with NEQAIR ${ }^{13,14}$ as shown in Figure 23. The simulation was performed for different couples of rotational and vibrational temperature for $\mathrm{CN}$. No information about the electronic excitation can be gained because all $\mathrm{CN}$ emission in the measured wavelength range come from the same electronically excited level (electronic transition $\mathrm{B}^{2} \Sigma \rightarrow \mathrm{X}^{2} \Sigma$ ). The temperature determination results from a comparison of intensity-normalized spectra by comparing the spectral band shape. The measured spectra represent line-of-sight values integrating the emission throughout the radial extent of the post shock layer. By comparing the measured spectra to simulated spectra at a given temperature couple, radial temperature gradients are neglected. Therefore, the temperatures obtained from these considerations are considered estimates of an average temperature, although the averaging will be non-linear and dominated by the peak temperatures. The database for the $\mathrm{CN}$ simulation was therefore computed with temperature increments of $1,000 \mathrm{~K}$. Through independent variation of rotational and vibrational temperatures, non-equilibrium effects were included, although the results indicate the post shock layer being close to equilibrium as far as rotational and vibrational excitation are concerned. For a preliminary analysis, temperatures were determined through manually fitting simulated and measured spectra for a frame shortly after model insertion. A procedure for automatically fitting spectra is under development. Table 2 summarizes the temperatures in the post-shock layer in front of different models and materials as obtained so far.

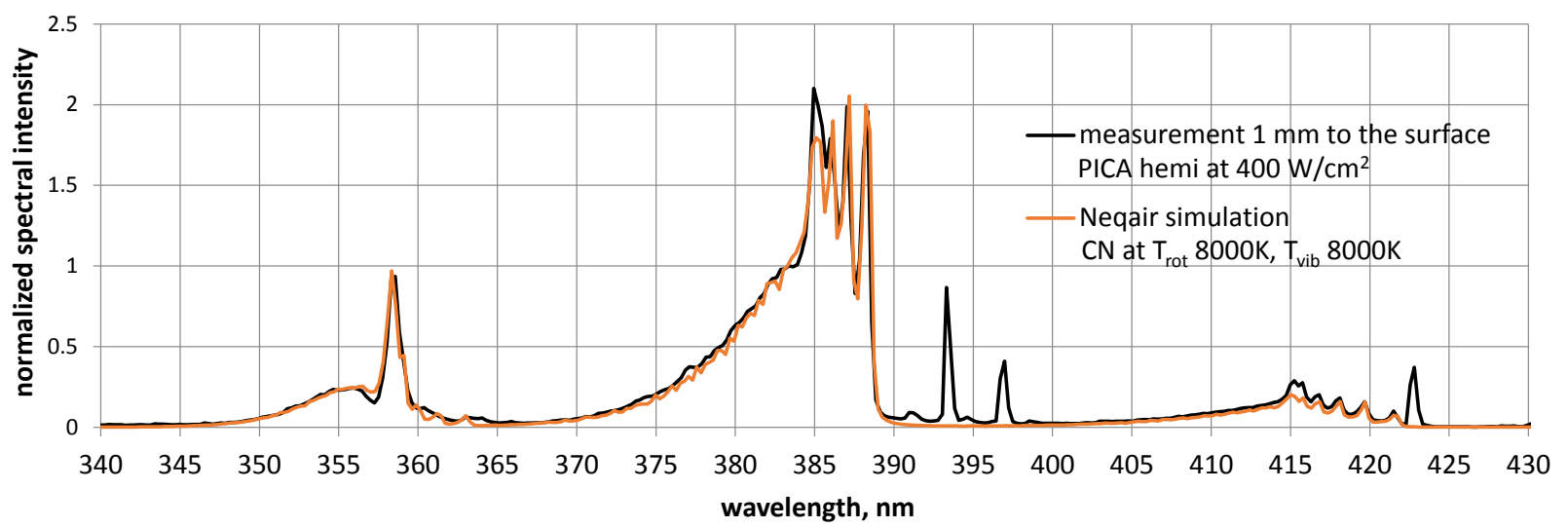

Figure 23. Measured spectrum at $1 \mathrm{~mm}$ distance to a hemispherical PICA sample at $400 \mathrm{~W} / \mathrm{cm}^{2}$. And CN spectrum simulated with NEQAIR for $T_{\text {rot }}=8,000 \mathrm{~K}$ and $T_{\text {vib }}=8,000 \mathrm{~K}$, normalized to their respective value at $384 \mathrm{~nm}$.

Table 2. Rotational and vibrational temperatures ( $\left.\mathbf{T}_{\text {rot }} / \mathbf{T}_{\mathbf{v i b}}\right)$ from $\mathrm{CN}$ emission.

\begin{tabular}{lcccccc}
\hline \hline $\begin{array}{c}\text { Distance } \\
\text { to the } \\
\text { surface }\end{array}$ & $\begin{array}{c}\text { PICA hemi, } \\
200 \mathrm{~W} / \mathrm{cm}^{2}\end{array}$ & $\begin{array}{c}\text { FF hemi, } \\
200 \mathrm{~W} / \mathrm{cm}^{2}\end{array}$ & $\begin{array}{c}\text { PICA hemi, } \\
400 \mathrm{~W} / \mathrm{cm}^{2}\end{array}$ & $\begin{array}{c}\text { FF hemi, } \\
400 \mathrm{~W} / \mathrm{cm}^{2}\end{array}$ & $\begin{array}{c}\text { PICA cyl, } \\
200 \mathrm{~W} / \mathrm{cm}^{2}\end{array}$ & $\begin{array}{c}\text { FF cyl, } \\
200 \mathrm{~W} / \mathrm{cm}^{2}\end{array}$ \\
\hline $0.5 \mathrm{~mm}$ & $8,000 / 8,000$ & $7,000 / 7,000$ & $8,000 / 8,000$ & $8,000 / 8,000$ & $7,000 / 7,000$ & $7,000 / 7,000$ \\
$1 \mathrm{~mm}$ & $8,000 / 8,000$ & $7,000 / 7,000$ & $9,000 / 9,000$ & $9,000 / 9,000$ & $7,000 / 7,000$ & $7,000 / 7,000$ \\
$1.5 \mathrm{~mm}$ & $8,000 / 8,000$ & $7,000 / 7,000$ & $9,000 / 9,000$ & $9,000 / 9,000$ & $7,000 / 7,000$ & $7,000 / 7,000$ \\
$2 \mathrm{~mm}$ & & & $10,000 / 9,000$ & $10,000 / 9,000$ & $7,000 / 7,000$ & $7,000 / 7,000$ \\
$2.5 \mathrm{~mm}$ & & $10,000 / 10,000$ & $10,000 / 9,000$ & $7,000 / 7,000$ & $7,000 / 7,000$ \\
$3 \mathrm{~mm}$ & & & & $7,000 / 7,000$ & $7,000 / 7,000$ \\
\hline \hline
\end{tabular}

\section{Spalled Particle Temperatures}

As illustrated in Fig. 3, emission spectra were also acquired along the sample sidewall with the goal of obtaining information on spalled particles. Observing the continuum emission from the glowing particles enables calculation of the average particle temperature. These measurements are a complement to particle trajectories measurements obtained using high-speed imaging. ${ }^{4}$ In this section we describe the preliminary developments of a data analysis procedure for determination of particle temperature measurements.

Figure 24 shows spectra at an offset position above a cylindrical FiberForm sample in the plasma flow about 2 seconds after sample insertion into the plasma at a heat flux of $200 \mathrm{~W} / \mathrm{cm}^{2}$. The emission spectra show distinct Planck emission in the visible wavelength regions which are assigned to grey body emission from the spalled particles

American Institute of Aeronautics and Astronautics 
in the plasma flow. Note that the glowing surface of the test sample is not in the field of view of the spectrometer in this configuration, therefore the observed continuum emission is indeed assigned to particles in the flow. However, typical exposure times were hundreds of milliseconds so the measured spectra are most certainly produced by many particles. This Planck emission is strongest at the upstream edge of the image close to the shock front and decreases downstream. The second major contributor to the spectra is $\mathrm{CN}$ emission which shows a maximum downstream the shock, close to the edge of the sample. Close to the shock, the $\mathrm{CN}$ signal is weaker.

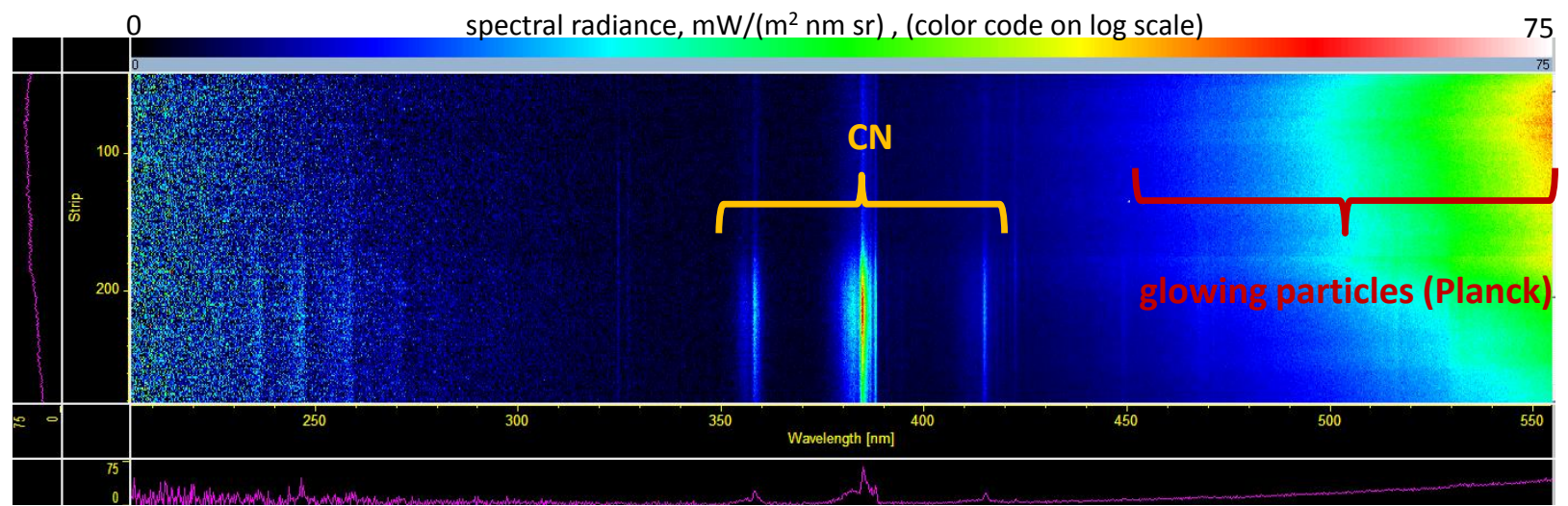

Figure 24. Spectral image of a line of detection parallel to the side of a cylindrical FiberForm sample at about $2 \mathrm{~s}$ after insertion into the plasma (flow direction is from top to bottom).

As demonstrated in Ref. 4, individual spectra can be manually fitted with Planck emission to yield the desired spectra. For the fitting procedure, grey behavior is assumed for the emissivity of the spalled particles. Several automated procedures were tested in order to improve the performance of the fitting procedure and achieve the desired accuracy.

In a first approach, Planck emission was calculated for temperatures between $1,500 \mathrm{~K}$ and 4,500 $\mathrm{K}$ with temperature increments of $50 \mathrm{~K}$. From these spectra, the ratio between two different spectral positions can be determined (here, $440 \mathrm{~nm}$ and $540 \mathrm{~nm}$ were chosen). If the corresponding ratio is determined from the measured data, temperatures can be directly extracted through interpolating the calculated Planck emission ratios. This method is analogous to two-color pyrometry, therefore it will be referred to as the two-color method in the following.

Figure 25 shows the temperatures obtained with the two-color procedure for the spectra shown in Fig. 24 as a function of vertical position on the CCD array. Close to the shock at the upper edge of the measured line, the particle temperatures exceed $3,000 \mathrm{~K}$, but quickly approach a nearly constant value of 2,200 $\mathrm{K} \pm 150 \mathrm{~K}$ slightly decreasing in the downstream direction.

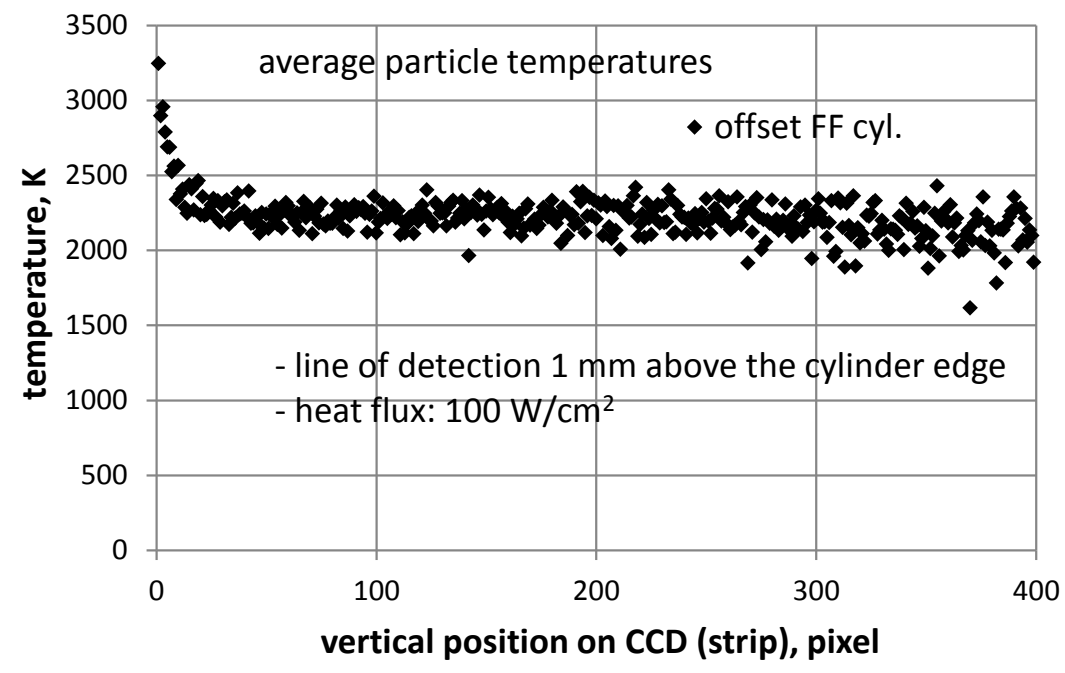

Figure 25. Particle temperatures determined by fitting Planck radiation with the two-color method along an observation line $1 \mathrm{~mm}$ above a hemispherical FiberForm sample at a heat flux of $100 \mathrm{~W} / \mathrm{cm}^{2}$.

American Institute of Aeronautics and Astronautics 
The second data set chosen for analysis was a line of detection slightly above the straight edge of a FiberForm wedge at a heat flux of $200 \mathrm{~W} / \mathrm{cm}^{2} 19$ seconds after model insertion. The measured spectral image is shown in Fig. 26. The spectra are dominated by continuum radiation with weak contributions from $\mathrm{CN}$. In addition to the two-color method, a Matlab analysis was implemented. In particular, a restriction was adopted to prevent the difference between measured data and fitting continuum emission from showing negative values. This difference is the line emission due to atoms and molecules which should never become negative. All spectra were normalized to $430 \mathrm{~nm}$ and two Planck spectra were fit, one towards lower and one towards higher wavelengths. The reported temperatures are the average of those two fits, and the differences to this average temperature are interpreted as error bars. Both methods were applied to the wedge data set. As shown in Fig. 26, the measured intensities are rather low for strips less than 215 and higher than 250 which certainly increases the errors in temperature. The results are plotted in Fig. 27, showing the temperature as function of Y-position on the CCD array. Values above $3000 \mathrm{~K}$ were computed upstream of the wedge tip and decreasing temperatures to $2200 \mathrm{~K} \pm 200 \mathrm{~K}$ were determined in the downstream region. They agree rather well, except for values around strip 300 where the Matlab analysis shows increasing temperatures in downstream direction which is not seen if the interpolated Planck ratios are used. Figure 28 shows examples of measured spectra and corresponding Planck emission obtained with both methods.

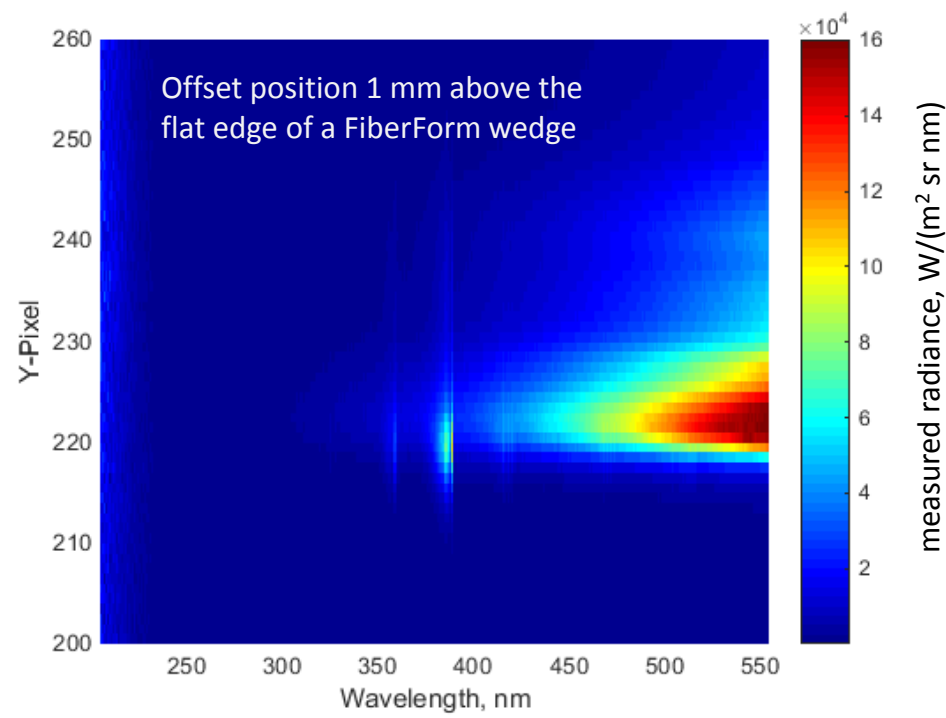

Figure 26. Spectral image of a line of detection parallel to the side of a cylindrical FiberForm sample at about $2 \mathrm{~s}$ after insertion into the plasma (radiance displayed with a color code on log scale).

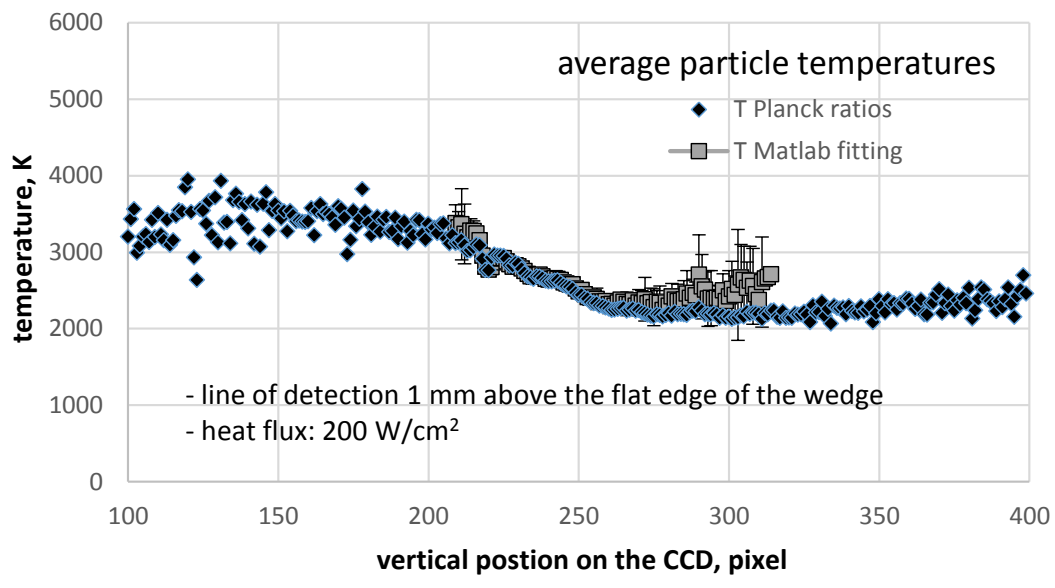

Figure 27. Particle temperatures determined by fitting Planck radiation along an observation line $1 \mathrm{~mm}$ above the straight edge of FiberForm wedge sample at a heat flux of $200 \mathrm{~W} / \mathrm{cm}^{2}$ determined by using interpolated Planck ratios and constraint Matlab fitting.

American Institute of Aeronautics and Astronautics 

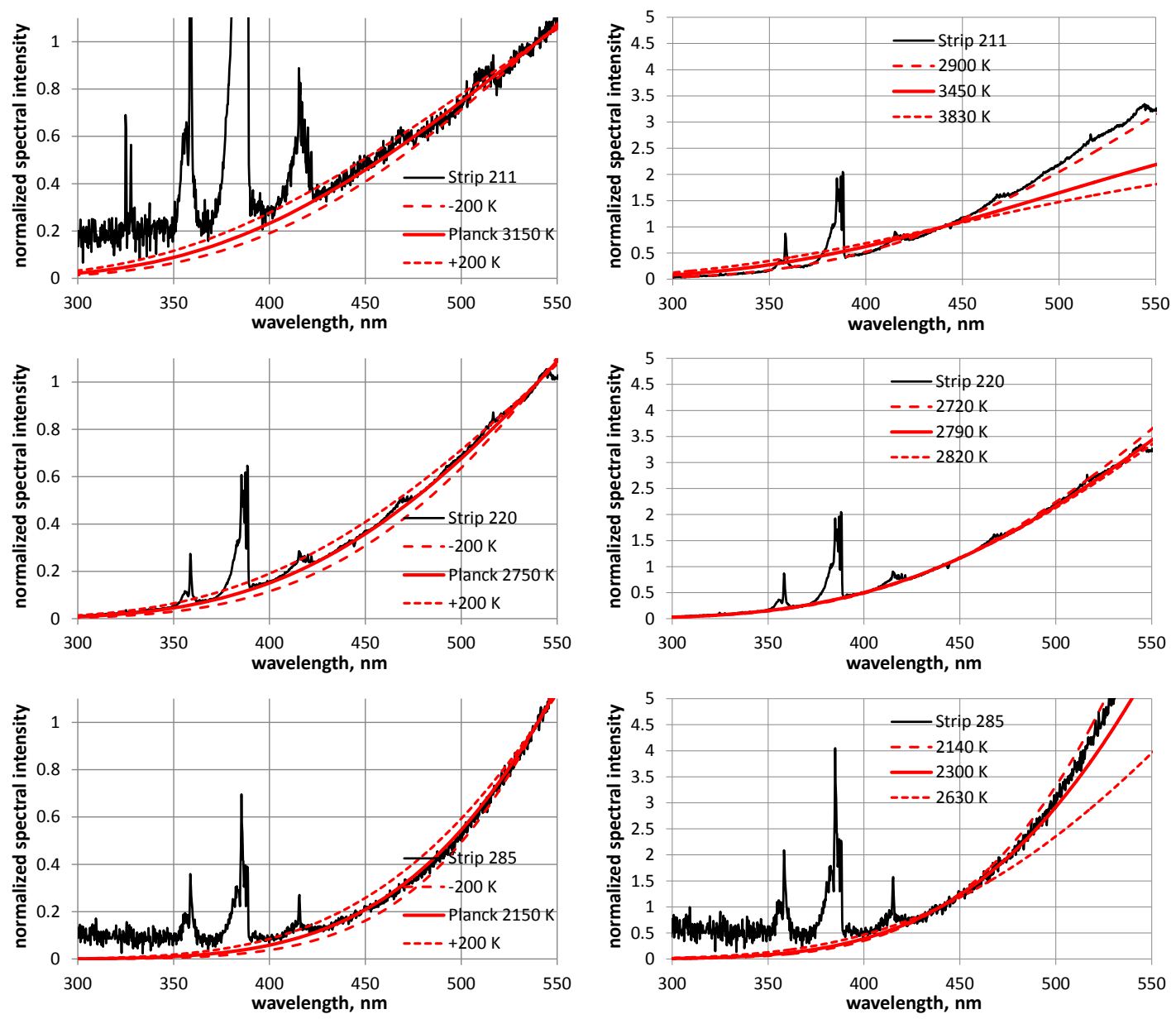

Figure 28. Examples for measured spectra and fitting Planck curves using the two-color method (left) and the Matlab code for fitting two separate Planck curves (right).

American Institute of Aeronautics and Astronautics 


\section{Summary and Conclusions}

Emission spectroscopy measurements in the post-shock layer in front of PICA and FiberForm samples of different shapes were carried out in the NASA Langley HYMETS arcjet facility with hemispherical, cylindrical and wedge shaped samples. The emission signatures in front of PICA and FiberForm were monitored along the stagnation line in front of the hemispherical and cylindrical samples. The distribution along the stagnation line of line and band emission of $\mathrm{CN}, \mathrm{C}, \mathrm{NH}, \mathrm{H}, \mathrm{Ca}$, and $\mathrm{Ca}+$ were monitored for heat flux values of 200 and $400 \mathrm{~W} / \mathrm{cm}^{2}$. Hydrogen containing species as an indicator for pyrolysis gases were only seen in front of PICA. Their emission peaks right after model insertion and decreases significantly over test time, this effect being strongest for the highest heating rate. A possible explanation is that, with the migration of the pyrolysis zone towards the inside of the material, at least part amount of the pyrolysis gases escapes through the side walls of the models and not through the front. $\mathrm{CN}$ and $\mathrm{C}$ emission stays roughly constant over test time (atomic carbon emission being present mainly at the highest heat flux). Those species are therefore considered to be mainly produced by interactions of the carbon fibers with the impinging plasma.

Temperature estimates of the post-shock layer plasma were obtained from analysis of $\mathrm{CN}$ band emission through comparison with NEQAIR simulation. Temperature values of about 6,000 to 7,000 $\mathrm{K}$ were seen in the post-shock layer in front of cylindrical samples at a heat flux of $200 \mathrm{~W} / \mathrm{cm}^{2}$ with no significant variation with distance to the sample surface. For hemispherical models the corresponding temperatures were on the order of 7,000 K. For hemispherical models at a heat flux of $400 \mathrm{~W} / \mathrm{cm}^{2}$, the plasma temperatures were about $2,000 \mathrm{~K}$ higher with a slight increase with increasing distance to the surface. In all cases, rotational and vibrational temperatures were close to each other indicating a plasma close to thermal equilibrium. No information on the electronic excitation temperatures were available from the $\mathrm{CN}$ measurements.

In addition to the stagnation line configurations, off-axis lines of observation were investigated to gather information about spalled particles in the flow. From a comparison of measured continuum emission with simulated Planck radiation, average particle temperatures along the measured line of observation were determined for two cases. Particle temperatures between 3,500 and 2,000 K were found. A comprehensive investigation of these temperatures for all cases available is ongoing.

The data provided is intended for a comparison with numerical simulation of the stagnation flow around these models, in particular for the validation of material response models. Results from these numerical simulations will have to be used for a spectral simulation which then can be compared to the results presented in this work.

\section{Acknowledgments}

Financial support for the experimental work at NASA Langley and the spectral analysis was provided by NASA Kentucky EPSCoR Award NNX10AV39A. The authors would like to thank M.J. Wright, N.N. Mansour, G. Gonzales, J. Wang, J. Seibert, and J. Mach from NASA Ames Research Center for their support, F. Taylor and H. Mefford at the University of Kentucky for their assistance in designing and machining many of the components necessary for this project, and $\mathrm{H}$. Koch for his help in preparing the measurement campaign. Finally, the authors are grateful to W. Geouge and J. Gragg for their immense support during testing at NASA Langley Research Center.

\section{References}

${ }^{1}$ Terrazas-Salinas, I., "Test Planning Guide for NASA Ames Research Center Arc Jet Complex and Range Complex," Space Technology Division, NASA Ames Research Center, Moffett Field, CA 94035.

${ }^{2}$ Bose, D., Skokova, K., Wright, M.J., Reuther, J., "Ground-to-Flight Traceability Analysis of Arcjet Testing for the Crew Exploration Vehicle," AIAA 2009-3845, 41 st AIAA Thermophysics Conference, 22-25 June 2009, San Antonio, Texas. DOI: $10.2514 / 6.2009-3845$

${ }^{3}$ Martin, A., Bailey, S. C. C., Panerai, F., Davuluri, R. S. C., Vazsonyi, A. R., Zhang, H., Lippay, Z. S., Mansour, N. N., Inman, J. A., Bathel, B. F., Splinter, S. C., and Danehy, P. M., "Numerical and experimental analysis of spallation phenomena," CEAS Space Journal, Vol. 8, No. 2, June 2016.

DOI: $10.1007 / \mathrm{s} 12567-016-0118-4$

${ }^{4}$ Martin, A., Bailey, S.C.C., Panerai, F., Winter, M., Bauer, D., Davuluri, R.S.C., Zhang, H., Splinter, S., and Danehy, P., "Numerical and experimental analysis of the spallation phenomenon," presentation at the $7^{\text {th }}$ Ablation Workshop, October 21-22 2015, Tullahoma, TN.

${ }^{5}$ Weng, H., Bailey, S.C.C., and Martin, A., "Numerical study of iso-Q sample geometric effects on charring ablative materials," International Journal of Heat and Mass Transfer, Vol. 80, January 2015, pp. 570-596

DOI: 10.1016/j.ijheatmasstransfer.2014.09.040

${ }^{6}$ Lachaud, J. and Mansour, N. N., "Porous-Material Analysis Toolbox Based on OpenFOAM and Applications," Journal of Thermophysics and Heat Transfer, Vol. 28, No. 2, April 2014, pp. 191-202.

DOI: $10.2514 / 1 . T 4262$

American Institute of Aeronautics and Astronautics 
${ }^{7}$ Davuluri, R. S. C., Zhang, H., and Martin, A., "Numerical study of spallation phenomenon in an arc-jet environment," Journal of Thermophysics and Heat Transfer, Vol. 30, No. 1, January 2016, pp. 32-41.

DOI: $10.2514 / 1$.T4586

${ }^{8}$ Fu, R., Weng, H., Wenk, J. F., and Martin, A., “Application of A New Thermal-Mechanical Coupling Solver for Ablation," AIAA Paper, 46th AIAA Thermophysics Conference, Washington, D.C., June 2016.

${ }^{9}$ Danehy, P. M., Hires, D. V., Johansen, C. T., Bathel, B. F., Jones, S. B., Gragg, J.G. and Splinter, S. C., "Quantitative Spectral Radiance Measurements in the HYMETS Arc Jet", Paper AIAA-2012-856 presented at the 50 ${ }^{\text {th }}$ AIAA Aerospace Sciences Meeting, Nashville TN, Jan 9-12, 2012.

${ }^{10}$ Empey, D., Skokova, K., Agrawal, P., Swanson, G., Prabhu, D., Peterson, K., Winter, M., Venkatapathy, E., "Small Probe Reentry Investigation for TPS Engineering (SPRITE)," AIAA-2012-0215, 50th AIAA Aerospace Sciences Meeting, Nashville, Tennessee, 9-12 Jan 2012.

DOI: $10.2514 / 6.2012-215$

${ }^{11}$ Splinter, S. C., Bey, K. S., Gragg, J. G., Brewer, A., "Comparative Measurements of Earth and Martian Entry Environments in the NASA Langley HYMETS Facility,” AIAA Paper 2011-1014, 49th AIAA Aerospace Sciences Meeting, January 4-7, 2011, Orlando, FL, 2011

DOI: $10.2514 / 6.2011-1014$

${ }^{12}$ Johansen, C., Lincoln, D., Bathel, B., Inman, J., Danehy, P., "Simultaneous Laser-Induced Fluorescence of Nitric Oxide and Atomic Oxygen in the Hypersonic Materials Environment Test System Arcjet Facility," $17^{\text {th }}$ International Symposium on Applications of Laser Techniques to Fluid Mechanics, Lisbon, Portugal, 07-10 July, 2014.

${ }^{13}$ Whiting, E E, Park, C, Liu, Y, Arnold, J O, and Paterson, J A, "NEQAIR96, Nonequilibrium and Equilibrium Radiative Transport and Spectra Program: User's Manual," NASA RP-1389, NASA, December 1996.

${ }^{14}$ Brandis, A., Cruden, B., "NEQAIR Tutorial," Educational Event, AIAA AVIATION 2014, Atlanta, GA, May 21-25 2012.

${ }^{15}$ Lachaud, J., Mansour, N. N., Ceballos, A., Pejakovic, D., Zhang, L., Marschall, J.,"Validation of a volume-averaged fiberscale model for the oxidation of a carbon-fiber perform," AIAA-2011-3640, 42 ${ }^{\text {nd }}$ AIAA Thermophysics Conference, 27-30 June 2011, Honolulu, Hawaii.

${ }^{16}$ Panerai, F., Martin, A., Mansour, N. N., Sepka, S. A., and Lachaud, J., "Flow-Tube Oxidation Exper- iments on the Carbon Preform of a Phenolic-Impregnated Carbon Ablator," Journal of Thermophysics and Heat Transfer, Vol. 27, No. 2, April 2014, pp. 181-190.

DOI: $10.2514 / 1 . T 4265$

American Institute of Aeronautics and Astronautics 